\title{
Upper thermosphere winds and temperatures in the geomagnetic polar cap: Solar cycle, geomagnetic activity, and interplanetary magnetic field dependencies
}

\author{
T. L. Killeen, Y.-I. Won, R. J. Niciejewski, and A. G. Bums \\ Space Physics Research Laboratory, Department of Atmospheric, Oceanic and Space Sciences \\ University of Michigan, Ann Arbor
}

\begin{abstract}
Ground-based Fabry-Perot interferometers located at Thule, Greenland ( $76.5^{\circ} \mathrm{N}$, $\left.69.0^{\circ} \mathrm{W}, \Lambda=86^{\circ}\right)$ and at Søndre Strømfjord, Greenland $\left(67.0^{\circ} \mathrm{N}, 50.9^{\circ} \mathrm{W}, \Lambda=74^{\circ}\right)$ have monitored the upper thermospheric $(\sim 240-\mathrm{km}$ altitude) neutral wind and temperature over the northem hemisphere geomagnetic polar cap since 1983 and 1985, respectively. The thermospheric observations are obtained by determining the Doppler characteristics of the (O I) 15,867-K (630.0$\mathrm{nm}$ ) emission of atomic oxygen. The instruments operate on a routine, automatic, (mostly) untended basis during the winter observing seasons, with data coverage limited only by cloud cover and (occasional) instrument failures. This unique database of geomagnetic polar cap measurements now extends over the complete range of solar activity. We present an analysis of the measurements made between 1985 (near solar minimum) and 1991 (near solar maximum), as part of a long-term study of geomagnetic polar cap thermospheric climatology. The measurements from a total of 902 nights of observations are compared with the predictions of two semiempirical models: the vector spherical harmonic (VSH) model of Killeen et al. (1987) and the horizontal wind model (HWM) of Hedin et al. (1991). The results are also analyzed using calculations of thermospheric momentum forcing terms from the thermosphere-ionosphere general circulation model (TIGCM) of the National Center for Atmospheric Research (NCAR). The experimental results show that upper thermospheric winds in the geomagnetic polar cap have a fundamental diurnal character, with typical wind speeds of about $200 \mathrm{~m} \mathrm{~s}^{-1}$ at solar minimum, rising to up to about $800 \mathrm{~m} \mathrm{~s}^{-1}$ at solar maximum, depending on geomagnetic activity level. These winds generally blow in the antisunward direction, but are interrupted by episodes of modified wind velocity and altered direction often associated with changes in the orientation of the interplanetary magnetic field (TMF). The central polar cap ( $>>80$ magnetic latitude) antisunward wind speed is found to be a strong function of both solar and geomagnetic activity. The polar cap temperatures show variations in both solar and geomagnetic activity, with temperatures near $800 \mathrm{~K}$ for low $K p$ and $F_{10.7}$ and greater than about $2000 \mathrm{~K}$ for high $K p$ and $F_{10.7}$. The observed temperatures are significantly greater than those predicted by the mass spectrometer/incoherent scatter model for high activity conditions. Theoretical analysis based on the NCAR TIGCM indicates that the antisunward upper thermospheric winds, driven by upstream ion drag, basically "coast" across the polar cap. The relatively small changes in wind velocity and direction within the polar cap are induced by a combination of forcing terms of commensurate magnitude, including the nonlinear advection term, the Coriolis term, and the pressure gradient force term. The polar cap thermospheric thermal balance is dominated by horizontal advection, and adiabatic and thermal conduction terms.
\end{abstract}

\section{Introduction}

The wind and temperature structure of the Earth's upper thermosphere has been the subject of numerous theoretical and experimental investigations over the past 20 years, and many aspects of the climatology of this region of the atmosphere have been revealed. Measurements from the Dynamics Explorer 2 (DE 2) satellite which were made during 19811983, for example, demonstrated the behavior of the highlatitude thermosphere during solar maximum conditions [e.g., Killeen and Roble, 1988, and references therein]. The DE 2 data quantified the dependence of high-latitude thermospheric

Copyright 1995 by the American Geophysical Union .

Paper number 95JA01208.

0148-0227/95/95JA-01208\$05.00 winds and temperatures on geomagnetic and solar wind indices [McCormac et al., 1985, 1991; Killeen et al., 1991]. Measurements made by ground-based Fabry-Perot interferometers (FPIs) located at various auroral or near-auroral latitudes have also contributed to our understanding of the upper thermospheric dynamics at high latitudes [Rees at al., 1980, 1984a, b, 1987; Wickwar et al., 1984; Meriwether et al., 1983, 1984, 1988; McCormac and Smith, 1984; Smith et al., 1985, 1988, 1989; Stewart et al., 1985, 1988; Sica et al., 1986a, b, 1989; Wardhill and Jacka, 1986; Killeen et al., 1986; Hernandez et al., 1990, 1991; Hernandez and Killeen. 1988; Aruliah et al., 1991; Niciejewski et al., 1992, 1994].

These satellite and ground-based measurements have been extensively compared with theoretical predictions made from thermosphere-ionosphere general circulation models (TIGCMs) [e.g., Rees et al., 1984b, 1986, 1994; Roble et al., 1984. 1988a; Hays et al., 1984; Killeen et al., 1986; Fuller- 
Rowell et al., 1988, 1990; Rees and Fuller-Rowell, 1987; Fesen et al., 1991]. The discrepancies in experiment-model comparisons have motivated further improvements in the model specifications, leading to a fairly extensive quantitative understanding of the physical processes responsible for driving the upper thermospheric circulation. A review of the published literature, however, reveals significant limitations in the experimental coverage. For example, while the available satellite wind data provide coverage at all latitudes, they almost all pertain to near-solar-maximum conditions. Similarly, while long-term measurements from ground-based observatories are available at low latitudes [Burnside and Tepley, 1989], at middle latitudes [Hernandez and Roble, 1984; Buonsanto, 1991; Hagan, 1993; Hedin et al., 1994]. and at auroral latitudes [Ariulah et al., 1991], no long-term results have yet been presented from within the geomagnetic polar cap.

Thermospheric winds within the polar cap as a function of solar activity are of great interest for a number of reasons. The greatest wind speeds found anywhere within the Earth's atmosphere occur within the polar cap upper thermosphere, driven by ion drag associated with the magnetospheric convection electric field [e.g., Killeen et al., 1991]. The magnetospheric control also extends to lower thermospheric altitudes [Johnson and Luhmann, 1985; Johnson, 1990; Johnson and Virdi, 1991; Wiens et al., 1988; Killeen et al., 1992]. Because of the geometry of the polar cap magnetic field lines, the thermospheric winds respond rather directly to ion motions controlled by the solar wind/magnetospheric dynamo interaction. Because of inertia, however, the response is not immediate, but is rather measured in tens of minutes to hours. depending on ionization levels [Ponthieu et al., 1988]. Thermospheric polar cap winds also influence electrical feedback from the ionosphere to the magnetosphere via the "flywheel effect," wherein horizontal and field-aligned currents are modified by the presence of neutral winds whose speeds approach (or even at times exceed) ion drift speeds [Lyons at al., 1985; Deng et al., 1991, 1993; Thayer and Vickrey, 1992; Gary et al., 1994]. Deng et al. [1993] and Gary et al. [1994], for example, have both identified periods within the DE 2 mission lifetime when the polar cap neutral winds were sufficiently large to reverse the normal sign of the electrical power (Poynting) flux vector. At these times, the Poynting flux becomes out from, as opposed to into, the ionosphere. Thus polar cap thermospheric winds play a significant role in the bi-directional magnetosphere/ionosphere coupling.

To address the science issues discussed above, the University of Michigan operates two FPI observatories located in Greenland at Thule $\left(76.5^{\circ} \mathrm{N}, 69.0^{\circ} \mathrm{W}, \Lambda=86^{\circ}\right)$ and at Søndre Strømfjord $\left(67.0^{\circ} \mathrm{N}, 50.9^{\circ} \mathrm{W}, \Lambda=74^{\circ}\right)$. These observatories have monitored the upper thermospheric ( 240 $\mathrm{km}$ altitude) neutral winds and temperatures over the northern hemisphere geomagnetic polar cap since 1983 and 1985 , respectively. The Thule site is located well within the central geomagnetic polar cap (loosely defined here as the region $>80^{\circ}$ geomagnetic latitude), and the Søndre Strømfjord site is located near the auroral oval/polar cap boundary (see Figure 1). The thermospheric observations were obtained by determining the Doppler characteristics of the (O I) $15,867-\mathrm{K}(630.0-\mathrm{nm})$ emission of atomic oxygen. The instruments have operated on a routine, automatic, (mostly) untended basis during the winter observing seasons, with data coverage limited only by cloud cover and occasional instrument failures. This unique database

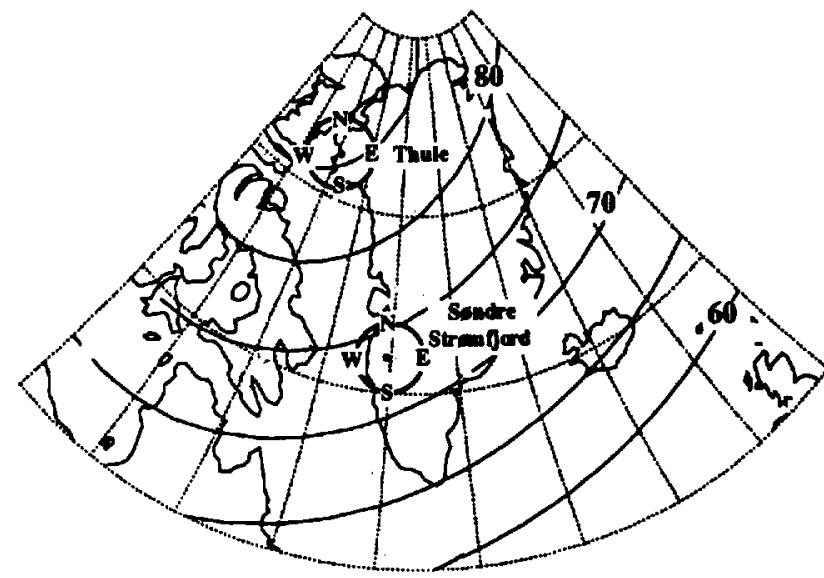

Figure 1. Map showing the location of the Thule and Søndre Stromfjord observatories as a function of geographic and geomagnetic latitude. The circles surrounding each site represent the "skyprints" for the Doppler wind observations of the atomic oxygen red line made at $45^{\circ}$ zenith angle in the geographic cardinal directions.

of geomagnetic polar cap measurements now extends over the complete range of solar activity (the latter being measured here by variations in the ground-based solar EUV flux index, $F_{10.7}$ ). We present an analysis of the measurements made between 1985 (near solar minimum) and 1991 (near solar maximum) inclusive, as part of a long-term study of geomagnetic polar cap thermospheric climatology. Measurements from a total of 902 nights of observations from the two sites are compared with the predictions of two semiempirical models: the vector spherical harmonic (VSH) model of Killeen et al. [1987, 1991] and the horizontal wind model (HWM) of Hedin ef al. [1991].

Various factors make this data set unique and of particular value for the study of magnetospheric coupling into the highlatitude neutral thermosphere. These factors are (1) the proximity of the Thule observing station to the geomagnetic pole, enabling polar cap thermospheric dynamics to be monitored over a long interval; (2) the continuous nature of the coverage owing to the high geographic latitude and polar night conditions; and (3) the long-term nature of the combined database, enabling solar cycle, geomagnetic activity, and interplanetary magnetic field (IMF) effects to be investigated separately.

The paper is organized as follows. Section 2 describes the FPI measurements and the nature of the long-term database from FPI observations at Thule and Søndre Stromfjord. Section 3 presents climatological results, using the averaged polar cap thermospheric winds and temperatures as a function of solar cycle, geomagnetic activity, and interplanetary magnetic field orientation. Section 4 provides a theoretical analysis of the momentum forcing terms responsible for the observed thermospheric structure. Section 5 is a short discussion and summary.

\section{Measurements}

The automated Fabry-Perot systems at Thule and Søndre Stromfjord have been described previously [Meriwether et al., 1983, 1988] and only a brief summary is given here. The Thule system is housed in a 24-foot transportable trailer on 
the Thule Air Base and has been operated since late 1985. The Søndre Strømfjord FPI is housed inside the building used to operate the incoherent scatter radar system and has been functional since February 1983. The interferometers both use a segmented anode image plane detector (IPD) [Killeen et al., 1983] and a 10-cm-diameter etalon to measure emission line profiles of the thermospheric (O I) $15,867-\mathrm{K}(630-\mathrm{nm})$ nightglow or auroral emission. The set of 12 detector channels spans a field of view of about $0.75^{\circ}$, which corresponds to about one and a half free spectral ranges (each channel samples a separate, contiguous spectral interval). While $630-\mathrm{nm}$ measurements have been obtained since the beginning of operations at both sites, the operating modes for both instruments were modified in 1988 to enable a "bifilter" mode, which involves time-shared measurements of the $630-\mathrm{nm}$ (upper thermospheric) and 557.7-nm (lower thermospheric) emissions. Results from the 557.7-nm measurements will be the subject of a forthcoming paper.

The etalon plates are optically contacted with posts of $1.116-\mathrm{cm}$ thickness. Band-pass filters of $3.5-\AA$ spectral width are used within an automated filter wheel to isolate each emission line of interest. The observing sequence consists of one zenith and four cardinal directions with a zenith angle of $45^{\circ}$. In each cycle, the dark count is also recorded. The time for a complete cycle takes about 10-20 min, depending on the emission brightness. A neon gas discharge lamp is used each cycle to measure any instrumental drift. The systems both have minimal drift ( $<30 \mathrm{~m} \mathrm{~s}^{-1}$ per night), and the drift is removed from the experimental measurements during the data analysis procedure. The zero-velocity reference is obtained using both a long-term ensemble of zenith measurements and averages from the four cardinal directions. Although this approach has potential limitations, particularly for auroral measurements, any systematic errors introduced for the polar cap measurements are likely to be less than $20 \mathrm{~m} \mathrm{~s}^{-1}$.

The wind and temperature values are derived from the lineof-sight observations using the analysis method of Killeen and Hays [1984]. The instrument function is measured periodically using a frequency-stabilized laser and deconvolved numerically from measured line profiles to provide the geophysical observables: wind, temperature, emission brightness, and continuum brightness. Data from the two sites are regularly inserted into the National Science Foundation (NSF) coupling, energetics, and dynamics of atmospheric regions ( CEDAR) data base at the National Center for Atmospheric Research (NCAR).

Two factors limited the amount of data obtained for this study. First, observations are possible only during nighttime conditions (solar zenith angle $>95^{\circ}$ ) and for cloud-free conditions. Cloud cover at both sites was monitored on an hourly basis at local meteorological facilities. Figure 2 shows the climatological cloud coverage from our detailed records. During the observing seasons (September-March), the skies are "clear" (defined as clouds over less than one third of the sky) for about 13 days per month at Thule and about 10 days per month at Søndre Strømfjord. As indicated in Figure 2, both sites are appreciably more cloudy during summer months. Second, the observations were occasionally limited, owing to equipment failures and instrumental problems. Since the Thule site is unmanned most of the time, failures there can lead to more severe data gaps. During the period of this study (September 1985-April 1991), a total of 902 nights of observations were included in the statistical study, including
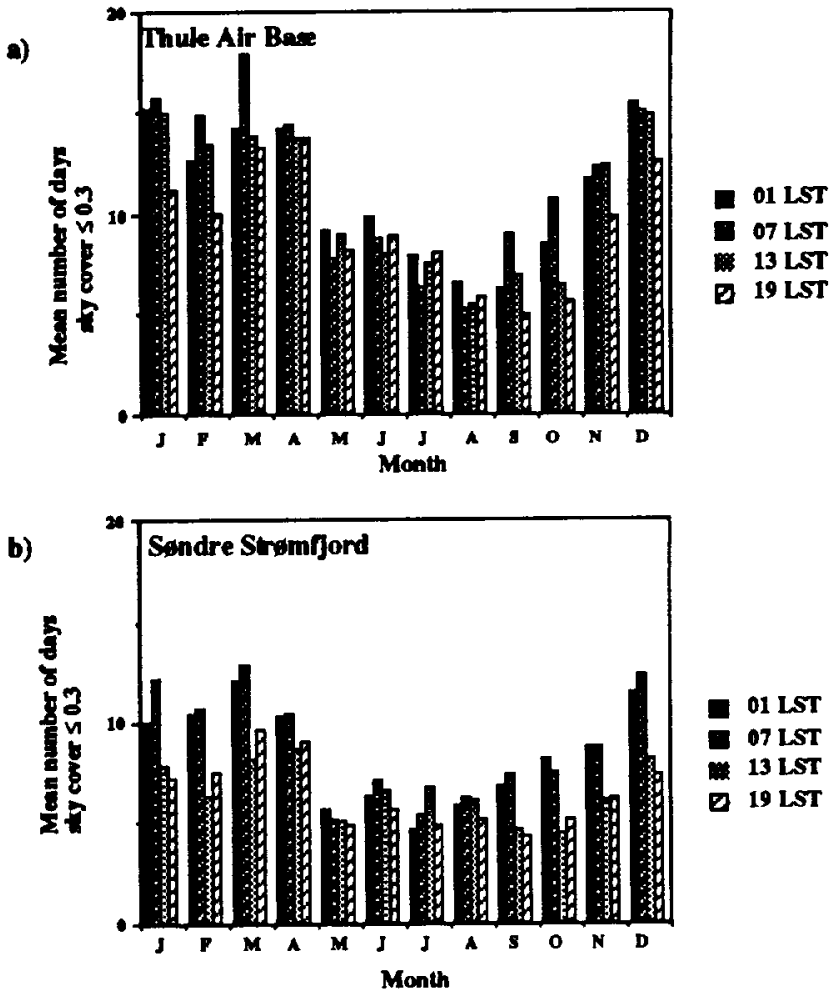

Figure 2. Mean cloud cover records for (a) Thule and (b) Søndre Strømfjord as a function of month of year. The data show the mean number of days for which clouds covered less than $30 \%$ of the sky. The cloud cover records are also plotted according to the specified local solar time (LST) bins.

411 nights (up to 24 hours of observations) at the Thule site and 491 nights at the Søndre Stromfjord site.

For the purposes of the present study, the entire database has been averaged into 1 -hour bins. Figure 3 shows an example of such hourly-averaged zonal and meridional winds measured at Thule during a 5-day period of clear skies during solar maximum conditions (see Figure 2 of Niciejewski et al. [1994] for the raw data). Other examples of multiday observations from Thule have been shown previously by Meriwether et al. [1988]. The data of Figure 3 illustrate typical upper thermospheric winds as measured in the central geomagnetic polar cap during solar maximum conditions $\left(F_{10.7}=230\right)$. Both zonal and meridional winds are normally strongly diumal in nature as indicated by the basic sinusoidal nature of the observed variations. The first-order wind dependence is one of simple diurnal rotation of the wind vector pointing in the approximately antisolar direction (wind speed of $400-500 \mathrm{~m} \mathrm{~s}^{-1}$ for this relatively high solar activity case). The sinusoidal nature of the observations is interrupted occasionally by transient deviations. An example of such a perturbation occurs near 1600 UT on day 352 , when the meridional wind abruptly changed from blowing northward at $\sim 100 \mathrm{~m} \mathrm{~s}^{-1}$ to having a very small magnitude for about 4 hours before returning to a northward speed of $-80 \mathrm{~m} \mathrm{~s}^{-1}$. This wind perturbation appear as a "bite-out" in the sinusoidal variation associated with antisunward flow. Figure 3 also shows the variations of the geomagnetic index $K p$ and the north-south component of the interplanetary magnetic field (IMF $B_{z}$ ). The bite-out in the meridional wind near 1600 UT on day 352 is associated with a similar disruption in the zonal wind profile 
THULE FPI : DAY\# 351-355 $1988(6300 \AA)$
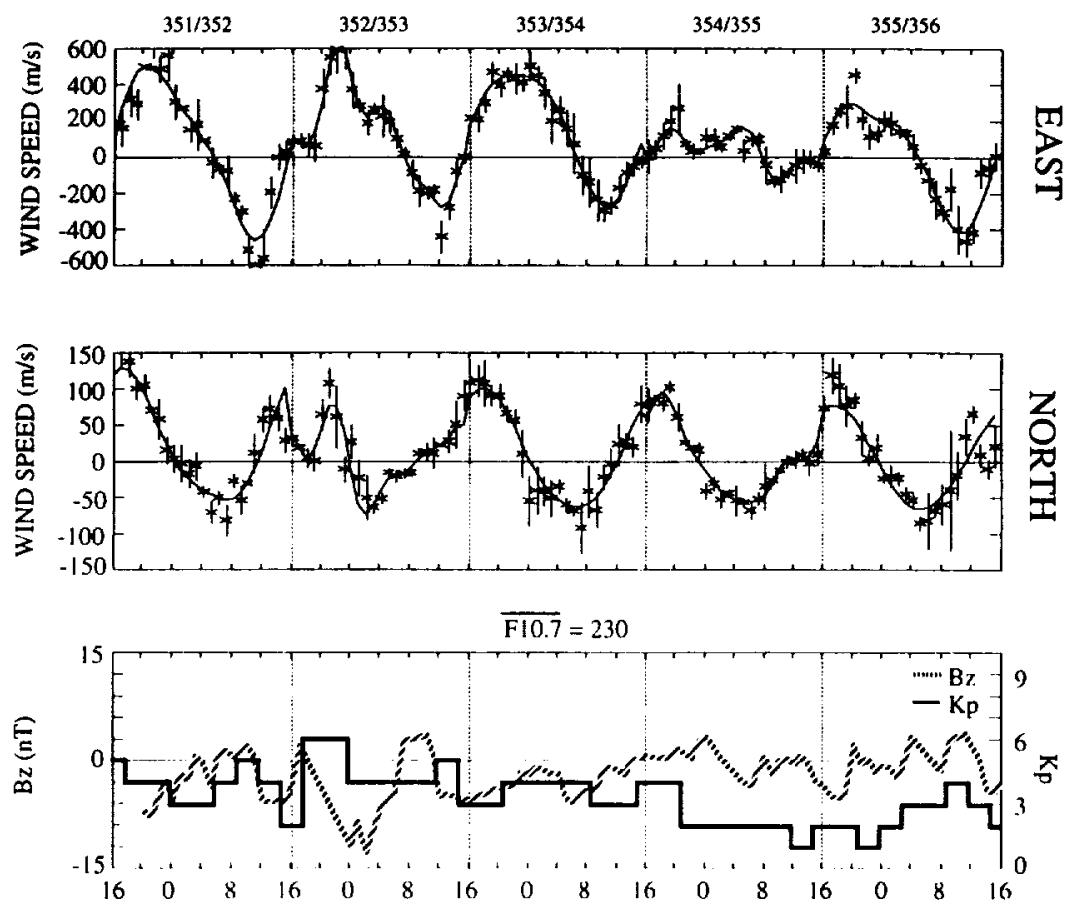

UNIVERSAL TIME (LT=UT-4)

Figure 3. Hourly-averaged thermospheric winds near $240-\mathrm{km}$ altitude measured above Thule, Greenland, during a cloud-free 5-day period in 1988. The top panel shows the geographic zonal winds (eastward positive), the middle panel shows the meridional winds (northward positive), and the bottom panel indicates the $K p$ and IMF $B_{z}$ for the 5-day period. Error bars represent calculated standard deviations. The solid lines in the upper two panels represent cubic spline fits to the averaged wind data.

and correlates in time with a brief northward turning of the IMF. We ascribe this and other perturbations from the simple diurnal sinusoidal signature to be due to the changed ionospheric convection pattern (and hence changed ion drag forcing of the neutral wind) during the short period of positive $B_{2}$. This dependence of the polar cap wind on the sign of the IMF $B_{z}$ is consistent with previous work [Killeen et al., 1985; McCormac et al., 1991; Niciejewski et al., 1994].

Figure 4 shows examples of observations of thermospheric temperatures over Thule for 24-hour periods during solar minimum (Figure 4a) and solar maximum (Figure 4b) conditions. The data are plotted according to the UT of the measurement (LT = UT - 4 hours). The error bars indicate the calculated uncertainty of each measurement, dominated by photon count statistics. As can be seen in the relative spacing of date points, the integration time used for each measurement is sutomatically adjusted to maintain a given statistical uncertainty (typically $\pm 15 \mathrm{~m} \mathrm{~s}^{-1}$ for winds and $\pm 30 \mathrm{~K}$ for temperatures), depending on the emission line brightness. Thus, near local midnight, the data points are more widely spaced. The data of Figure 4 show the expected increase in polar cap temperature during solar maximum. Some of the variations indicated in the data represent temperature gradients within the Thule FPI field of view, while others (e.g., the depression in temperature centered on $0700 \mathrm{UT}$ in the lower panel) represent the local time variations discussed by McCormac at al. [1988].
The multiyear database of measurements such as shown in Figures 3 and 4 has been reanalyzed with careful exclusion of data contaminated with clouds [Won, 1994]. Care was also taken to ensure that reliable, contemporaneous laser calibrations were used in the analysis procedure. All data were reanalyzed in a batch process recently to avoid problems associated with the use of multiple versions of analysis codes developed over a number of years. The large homogenous data set allows us to establish a climatology for the central polar cap upper thermosphere. The next section describes the principal results from this statistical study.

\section{Polar Cap Thermospheric Climatology}

\subsection{Solar Cycle Dependence of Polar Cap Winds}

Figure 5 shows the gross average wind patterns as measured by the FPIs at Thule and Sondre Stromfjord for each of the six winter observing seasons from 1985-1986 to 1990-1991 (Søndre Strømfjord measurements were not available for 1985 1986 and 1990-1991). The data are plotted in geomagnetic polar coordinates (geomagnetic latitude and local magnetic time (LMT)) and have been averaged into bins of 1-hour LMT width. These data represent the year-to-year variations in the mean thermospheric winds, including all levels of geomagnetic and solar activity. The data format provides two rings of vectors for each site, the inner ring coming from combining the pair of line-of-sight observations to the east 
Thule Air Base

Thermospheric Temperatures

a)

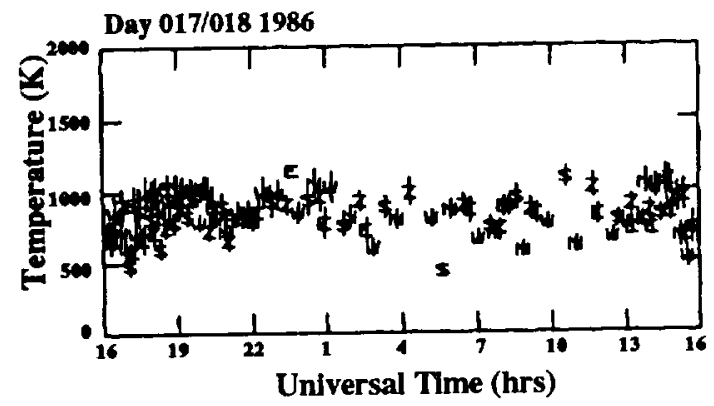

b)

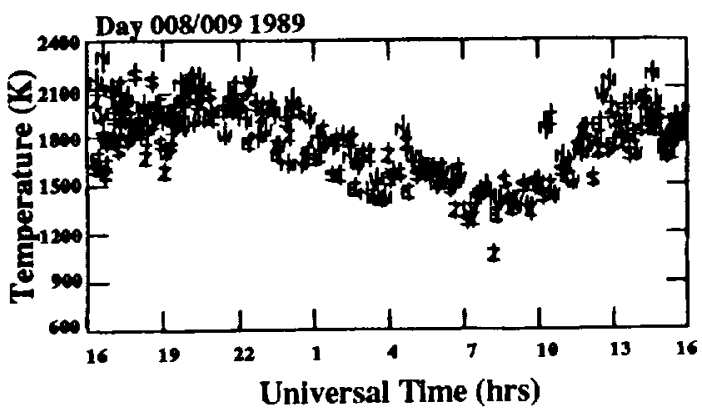

Figure 4. Thermospheric temperature observations from Thule during two 24-hour periods at (a) solar minimum and (b) solar maximum. The letters on each data point indicate the viewing direction for the particular observation ( $E$, east; $W$, west; N, north; S, south; $Z$, zenith). The error bars are the calculated uncertainties due to photon count statistics.

and north of the observing site and the outer ring coming from the observations to the south and west. Since Thule is at such high geomagnetic latitude, the corresponding vectors from Thule depict, in essence, the central geomagnetic polar cap flow.

The bottom panel in Figure 5 summarizes the variations of the solar EUV activity index $\left(F_{10.7}\right)$ and specifies the periods of useful observations each year (as shown by the shaded regions and by the year days for each observing period). As can be seen, the three observing seasons 1985-1986, 19861987 and 1987-1988 occurred during solar minimum conditions, with the solar $F_{10.7}$ index below 110. The transition to solar maximum conditions occurred fairly abruptly during 1988 , and the three later observing seasons (1988-1989, 1989-1990, and 1990-1991) can be conveniently classified to be roughly representative of solar maximum conditions. Typical averaged antisolar wind speeds over Thule during the early solar minimum period are $-200 \mathrm{~m}$ $\mathrm{s}^{-1}$. Typical wind speeds during the $1988-1989$ season are $-400 \mathrm{~m} \mathrm{~s}^{-1}$. The general enhancement in wind velocities observed in the 1989-1991 period relative to the 1985-1988 period was also evident in the winds measured at Søndre Stromfjord (outer pair of vector rings). Regions of sunward flow near dusk are seen in the Søndre Strømfjord averages, though no sunward flow ever occurs in the dawn sector averages. The maximum wind speeds generally occur in the early morning sector of the polar cap [Thayer and Killeen, 1991].

The greatest mean wind speeds were observed during the 1988-1989 season. Wind speeds during the 1990-1991 season were smaller in magnitude than either of the two preceding years (associated with a slight reduction in the $F_{10.7}$ level from peak values). The large mean winds observed in the early moming sector during 1986-1987, which indicate strong clockwise flow into the dawn sector, were not observed for any other year during the study. Further analysis of this anomaly is planned. One possible interpretation could involve a fundamental change in the force balance (between, for example, "ion drag" and "Coriolis" control), induced by unusually low ion densities. Sunward winds over Søndre Strømfjord in the evening hours were observed in all cases for which such data are available. No sunward flow was observed in the mean winds for the dawn sector.

\subsection{Geomagnetic Activity Dependence of Polar Cap WInds}

Figures 6 and 7 show two subsets of the data for low solar activity $\left(0<F_{10.7}<100\right)$ and high solar activity $\left(F_{10.7}>200\right)$, respectively. In these figures, the data have been further divided into the six specified levels of geomagnetic activity. The purpose of these plots is to depict the geomagnetic activity dependence of the polar cap mean winds for fixed levels of solar activity. These data are plotted in geographic polar coordinates (geographic latitude and local solar time (LST)). The averaged winds corresponding to intermediate levels of solar EUV flux index $\left(100<F_{10.7}<200\right)$ are not shown here, but are in the range between those depicted for the "low" and "high" averages of Figures 6 and 7, respectively, as one would expect.

Figure 6 illustrates the geomagnetic dependence of the polar cap winds for solar minimum conditions. While a significant number of observing sequences ("nights") are included in the four bins of lowest geomagnetic activity $(K p=1-4)$, relatively fewer data are available for the higher levels of geomagnetic activity $(K p=5,6)$, owing to the infrequency of large geomagnetic storms during solar minimum. The mean wind patterns indicate a prevailing antisunward flow over both Thule (inner pair of vectors) and Søndre Strømfjord (outer pair of vectors), with some indication of return sunward flows over Søndre Strømfjord in the dusk sector. While the mean winds at solar minimum show some signs of geomagnetic control, the dependence is rather weak, with only small increases in wind speeds (up to factors of 2) going from low to high geomagnetic activity (except perhaps for the $K p=6$ case, for which the data coverage is very sparse). Both the polar cap antisunward wind and the dusk sector return flow show modest increases with $K p$. The speed of the mean dusk sector sunward flow over Søndre Strømfjord increases with geomagnetic activity from values near $100 \mathrm{~m} \mathrm{~s}^{-1}$ at $K p=1$ to values near 200 $\mathrm{m} \mathrm{s}^{-1}$ for $K p=4$. No region of mean sunward flow is seen in the averages for $K p=5$, presumably owing to the general enlargement of the polar cap region and the consequent migration of the sunward flow region to lower magnetic latitudes.

The geomagnetic control of the polar cap winds is much more evident for the solar maximum case shown in Figure 7. During high levels of solar activity, the mean polar cap winds increase from near $200 \mathrm{~m} \mathrm{~s}^{-1}$ for $K p=1$ to near $800 \mathrm{~m} \mathrm{~s}^{-1}$ for $K p$ $=6$. The sunward flow over Søndre Strømfjord is only observed during low geomagnetic activity levels ( $K p \leq 2)$, with the exception of a single vector near $1700 \mathrm{LST}$ for the $K p=6$ average. In all cases, the flow is across the polar cap in a generally antisunward direction, with a slight offset toward the early morning hours and a tendency for counterclockwise 
AVERAGED THERMOSPHERIC NEUTRAL WIND FROM THULE AND SØNDRE STRØMFJORD (GEOMAGNETIC COORDS.)


Figure 5. Averaged thermospheric neutral winds from Thule Air Base and Søndre Strømfjord plotted in polar coordinates (geomagnetic latitude and local magnetic time) for the six observing seasons from 1985 to 1991. The outer circle is at $70^{\circ}$ geomagnetic latitude. The bottom panel shows the solar EUV flux activity index $F_{10} 7$ variations during this period and highlights the duration of each particular observing period (shaded regions). The number of nights included in each average is given just above and to the right of each polar dial (first number for Thule, second number for Søndre Strømfjord). The data illustrate the gross year-to-year dependence of polar thermosphere dynamics in magnetic polar coordinates.

rotation as the air crosses the polar region. Such a rotation is consistent with the effects of corotation, although the direction of flow is known to be a strong function of the IMF orientation (see below).

The differences between the two data sets shown in Figure 6 and 7 are striking and indicate that the polar thermosphere is much less responsive to changes in geomagnetic forcing at solar minimum than it is at solar maximum. Since most of the previously reported polar cap observations are from solar maximum, there exists a tendency to overestimate the effects of geomagnetic activity on polar cap winds during solar minimum. We believe that the present climatological results will provide a more correct baseline for polar cap wind modeling. In particular, the large average wind speeds observed at times of combined high geomagnetic and high solar activity levels (Figure 7) are of significance for studies of ionosphere-thermosphere-magnetosphere coupling, since the magnitudes approach, and may at times exceed, the corresponding magnitudes of the ion drifts in the same region.

To provide a concise summary of the combined dependence of polar cap winds on solar and geomagnetic activity, we have calculated the magnitude of the mean antisunward wind in the central polar cap (using the data from Thule Air Base) as a function of both the $F_{10.7}$ and $K p$ indices. The results of this analysis are shown in Figure 8 . The top three panels of this figure illustrate the dependence of the polar cap wind on geomagnetic activity level for three specified levels of solar activity (low, medium, and high). The data points in each case represent calculated means and standard deviations of the means. Calculated linear fits to the data are indicated and the 
$0<$ F $107<100$
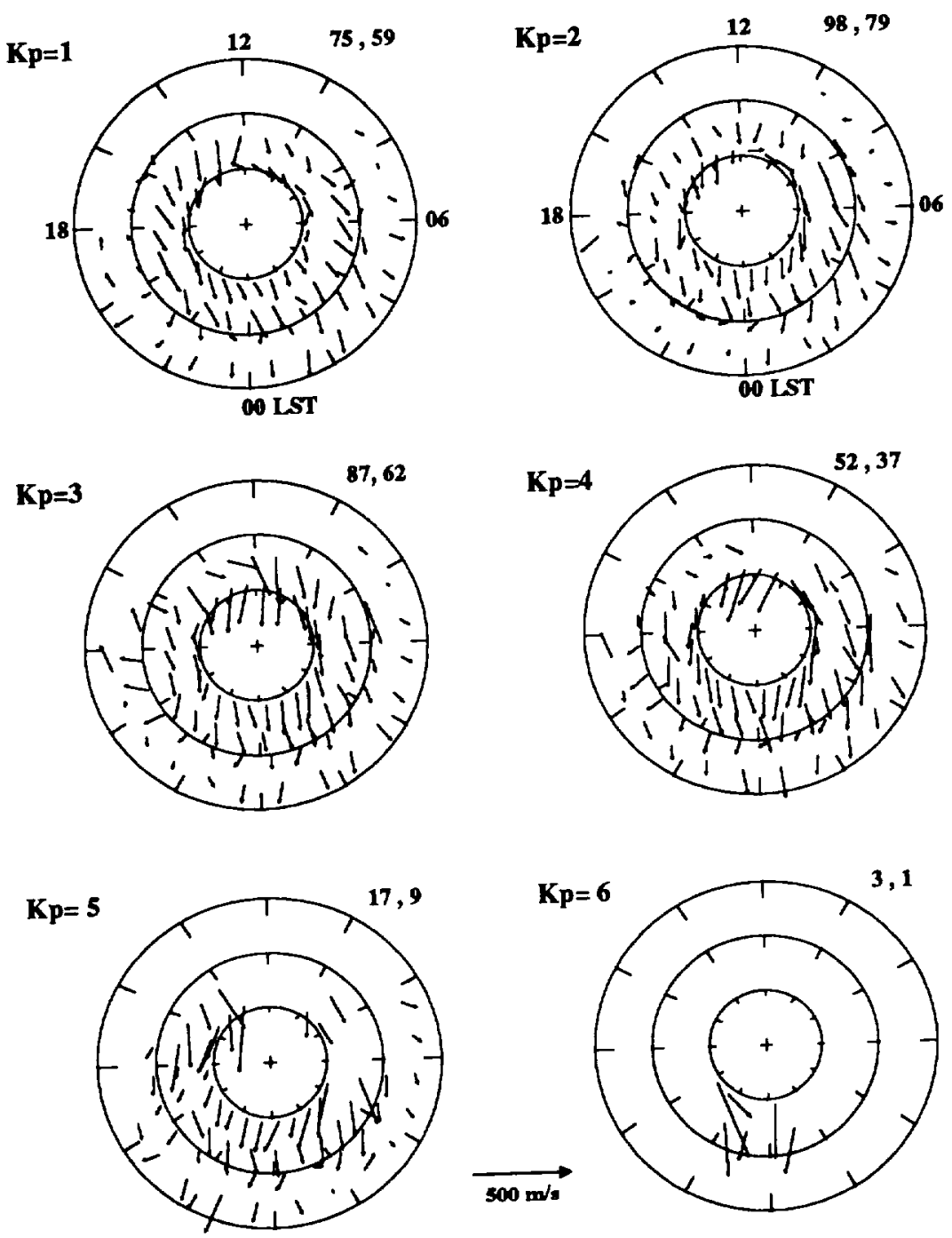

Figure 6. Averaged thermospheric neutral winds from Thule Air Base and Søndre Strømfjord plotted as a function of geomagnetic activity index $K p$ for conditions of low solar activity $\left(0 \leq F_{10.7} \leq 100\right)$. The data are plotted in polar coordinates (geographic latitude and local solar time). The number of nights included in each average is given just above and to the right of each polar dial (first number for Thule, second number for Søndre Stromfjord). The data represent the response of the polar cap winds to geomagnetic activity during solar minimum.

observations are compared with the predictions of the HWM and VSH semiempirical models. Although the linear fits provide only crude representations of the data, they are justified by the relatively large error bars and are useful in that they provide an estimation of the "sensitivity" of the polar cap wind to geomagnetic activity. For example, the linear fit indicates a sensitivity of $32 \mathrm{~m} \mathrm{~s}^{-1}$ per unit of $K p$ for the case of low solar activity (top left panel). This is much lower than the sensitivity for high solar activity $\left(93.6 \mathrm{~m} \mathrm{~s}^{-1} / \mathrm{Kp}\right)$. Thus this analysis would indicate a threefold increase in the sensitivity of the polar cap wind to geomagnetic activity at solar maximum over that at solar minimum. Our results for high solar activity are consistent, within stated errors, with those of McCormac et al. [1987a], who calculated a sensitivity of $68.7 \pm 30 \mathrm{~m} \mathrm{~s}^{-1} / K p$ from Dynamics Explorer data.

A good positive correlation between polar cap wind and geomagnetic activity level is seen in the top three panels of Figure 8. The calculated linear fit correlation coefficient $R$ indicates that the $\boldsymbol{K} \boldsymbol{p}$-wind correlation becomes stronger for high levels of solar activity. It is also noted that the regression line becomes steeper with increasing solar activity. An increase of unity in $K p$ corresponds to an increase in wind speed of about $40 \mathrm{~m} \mathrm{~s}^{-1}$ at solar minimum and about $100 \mathrm{~m} \mathrm{~s}^{-1}$ at solar maximum. However, the maximum average wind speeds during very quiet geomagnetic conditions $(K p=1)$ are close to $200 \mathrm{~m} \mathrm{~s}^{-1}$, regardless of solar activity.

The three lower panels of Figure 8 illustrate the sensitivity of the polar cap wind to solar activity for the three specified levels of geomagnetic activity. In most cases there is a positive correlation observed with both geomagnetic and solar activity and for both measurements and model calculations. Perhaps surprisingly, for low geomagnetic activity (bottom left-hand panel), our results indicate a negative correlation with solar activity (i.e., reduction in wind speed of $0.16 \mathrm{~m} \mathrm{~s}^{-1}$ per unit of $F_{10.7}$ ). We believe that this reversal of the normal trend is due to the influence of 
$200<$ F107
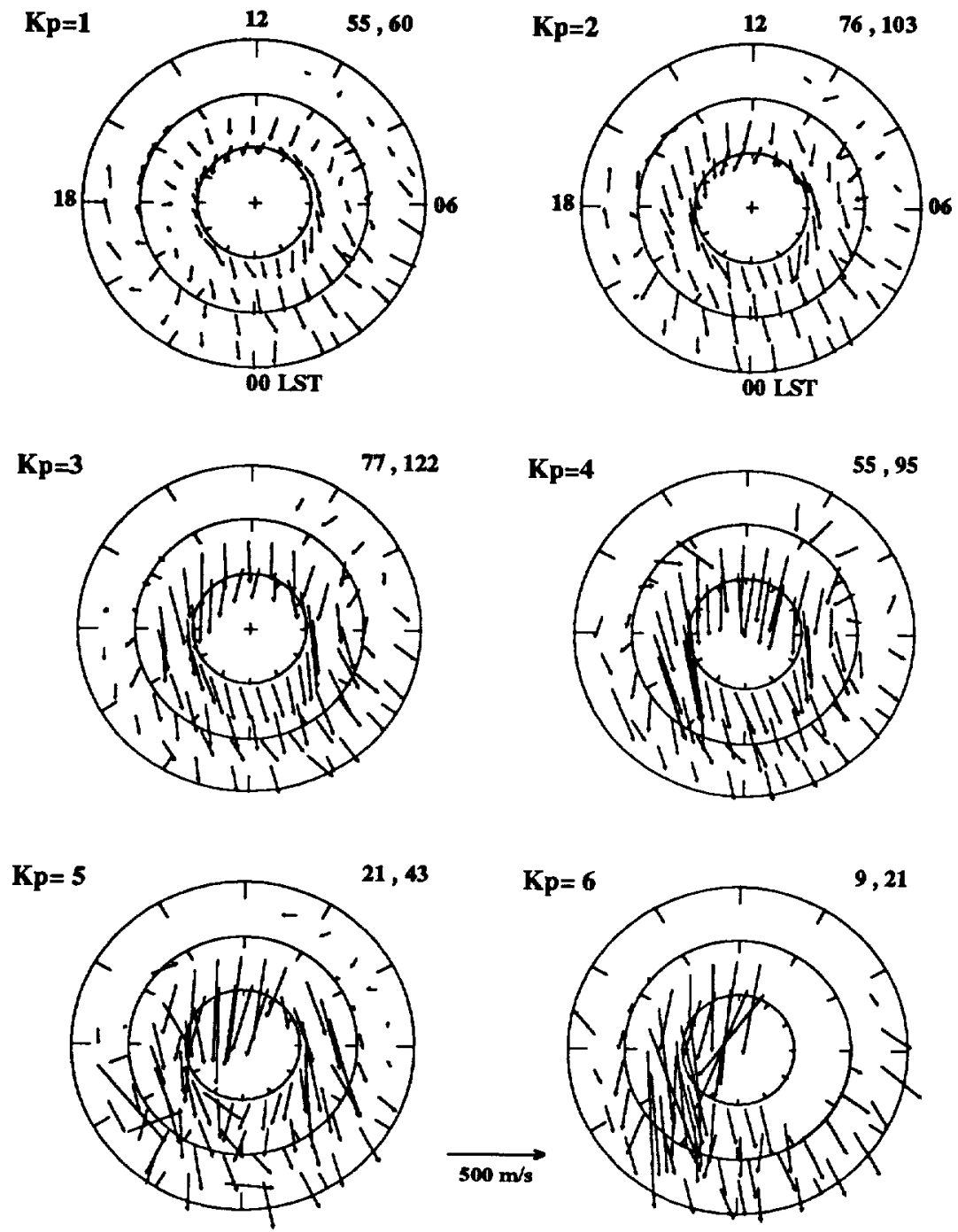

Figure 7. Averaged thermospheric neutral winds from Thule Air Base and Søndre Strømfjord plotted as a function of geomagnetic activity index $K p$ for conditions of high solar activity $\left(200 \leq F_{10.7}\right)$. The data are plotted in polar coordinates (geographic latitude and local solar time) for the six specified levels of geomagnetic activity. The number of nights included in each average is given just above and to the right of each polar dial (first number for Thule, second number for Søndre Stromfjord). The data represent the response of the polar cap winds to geomagnetic activity during solar maximum.

occasional sunward flows in the central polar cap associated with positive values for the IMF $B_{z}$ component. Sunward flows (or strongly moderated antisunward flows) have been seen in earlier satellite data [Killeen et al., 1985; McCormac et al., 1991] and ground-based data [Niciejewski et al., 1994].

We note here that, owing to the relatively large bin sizes for the data of Figure 8, some of the slope of the lines of $u_{\max }$ versus $\boldsymbol{K} \boldsymbol{p}$ in the upper three panels is due to the correlated increases of $F_{10.7}$ within the bin range (100 units of $F_{10.7}$ ). Similarly, some of the slope of the lines shown in the lower three panels is due to correlated increases of $K p$ within the bin range ( 2 units of $K p$ ). Thus the slopes of the regression line fits are to some degree (perhaps as much as $10 \%$ ) dependent on the sizes of the bins selected for this study. The slopes, therefore, should not be taken to represent the true independent sensitivity of maximum polar cap wind to the geomagnetic and solar flux indices.
The model results shown in Figure 8 were obtained by exercising the VSH and HWM codes for fixed solar and geomagnetic activity levels appropriate to the midpoints of the bins for each of the six cases shown. In general, the predictions bracket the observations, with the VSH and HWM models tending to overestimate and underestimate the winds, respectively. In the case of the lowest levels of solar and geomagnetic activity (bottom left-hand panel of Figure 8), the VSH model correctly predicts the observed anticorrelation, while the HWM model predicts a positive correlation in disagreement with the observations. The discrepancies between the model predictions and the observations can be explained, at least in part, by known shortcomings of the models. In the case of the HWM model, the limited number of spectral terms carried forward in the model description $(\sim 6)$ is insufficient to fully characterize the high spatial frequencies observed in high-latitude structures. Thus the HWM model 


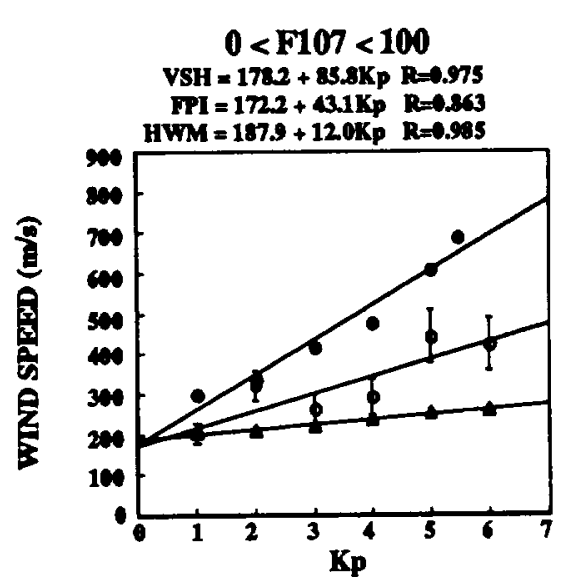

LOW Kp

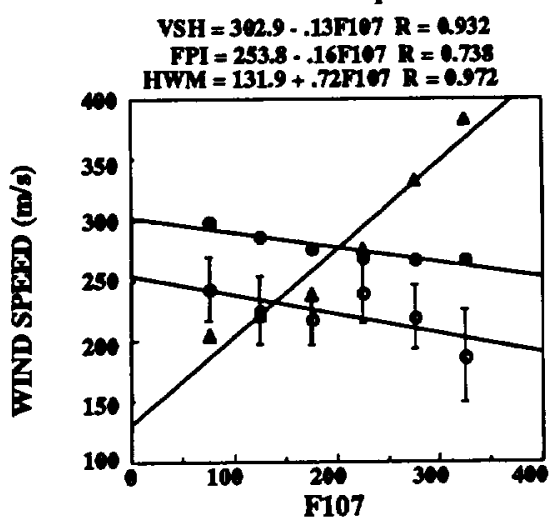

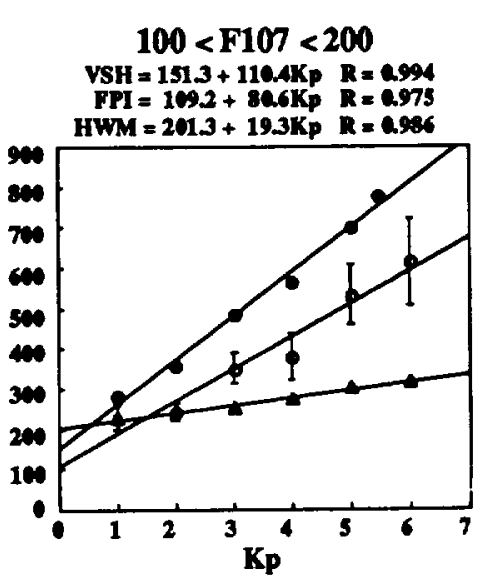

$100<\mathrm{F} 107<200$ VSH $=151.3+110.4 K p \quad R=2.994$ $F P I=109.2+84.6 \mathrm{Kp} \quad R=0.975$

MEDIUM Kp VSH $=415.1+.59 \% 107 \quad R=0.935$ $F P I=155.1+1.137107 \quad R=6.43$ $H W M=133.9+0.96167 \quad R=0.983$



$200<\mathrm{F} 107$

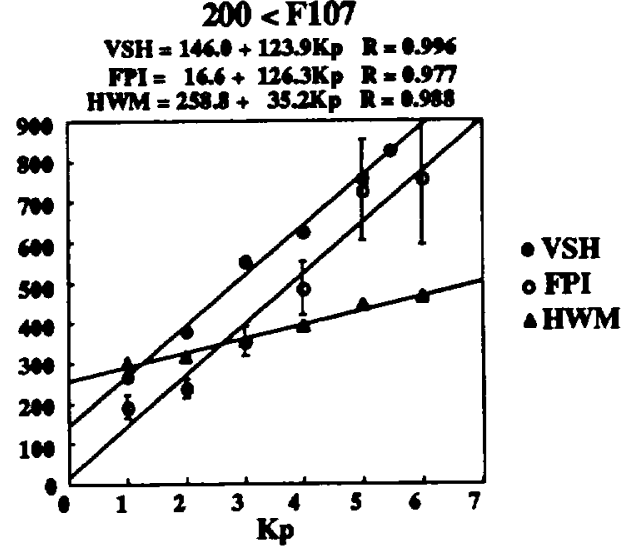

- VSH - FPI HWM

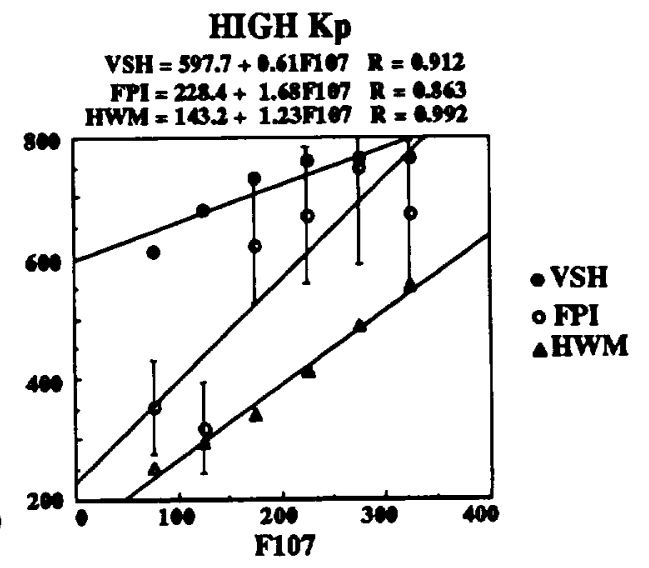

Figure 8. Comparison of the bin-averaged antisunward mean polar cap winds, as measured over Thule Air Base from 1985 to 1991 , with the predictions of the HWM and VSH semiempirical models. The data have been sorted according to the specified bin widths to illustrate $K p$ and $F, 10.7$ dependencies, separately. The lines and equations correspond to linear regression fits to the data and model predictions.

tends to smooth out large variations at high latitudes, leading to a reduction in magnitude for both auroral and polar cap winds. This relatively low spatial resolution for the HWM model may explain the fact that HWM seems to underestimate polar cap winds. In the case of the VSH model on the other hand, the number of spectral terms carried is much larger (30) and high-latitude spatial structures are largely preserved. However, the VSH model is derived from runs of the NCAR TIGCM that were extensively tuned to match observations made by the Dynamics Explorer 2 satellite at solar maximum. Relatively few measurements from solar minimum were available at the time of the initial development of the TIGCM and VSH codes. Thus one might expect the VSH comparisons to be most favorable at solar maximum. This is bome out by the perticularly good agreement between VSH predictions and the observations for the high soler activity case (top right panel of Figure 8).

\subsection{IMF $B_{y}$ Dependence of the Polar Cap WInds}

Figure 9 shows a subset of the experimental data sorted according to the sign of the east-west $\left(B_{y}\right)$ component of the IMF. The sign of the $B_{y}$ component is known to influence the relative size of the dawn and dusk ion convection cells and, thereby, the geometry of the neutral wind pattern [McCormac and Smith, 1984; Thayer et al., 1987; Niciejewski et al., 1992]. The data-sorting technique used for this presentation was similar to that used previously by Niciejewski et al.
[1992]. The IMF parameters used were 1-hour averages for both $B_{y}$ and $B_{z}$. Data were excluded if the IMF parameter was not available and if the $B_{z}$ component was positive and numerically greater than $+1 \mathrm{nT}$. The latter criterion was used to avoid complications due to the multicellular ion and neutral convection patterns that have been reported for strongly northward IMP [Killeen et al., 1985; Heppner and Maynard. 1987]. The neutral thermosphere has a variable response time to changes in ion drift, and there is a delay between the effects of the recorded IMF values changing the wind system. Thus rapid fluctuations in the IMF orientation will not normally be discernible in the neutral circulation. For this reason, we also only used data for which the sign of $B_{y}$ had remained constant for at least 2 hours preceding the wind measurement.

Figure 9 summarizes in geomagnetic polar coordinates the average neutral wind vectors for both positive and negative values of $B_{y}$ and for three levels of solar activity. The mean polar cap neutral winds show pronounced asymmetries which vary with $B_{y}$. For $B_{y}$ negative conditions, the cyclonic neutral vorticity associated with the dawn cell is strongly evident in the data from both observatories. For $B_{y}$ positive conditions, the anticyclonic neutral vorticity associated with the normally dominant dusk cell is strong. The sunward return flow in the dusk auroral zone is more evident for $B_{y}$ positive conditions than for $B_{y}$ negative conditions. There is no evidence of mean sunward return flow in the dawn sector in any of the averages. The IMF dependence is much stronger at solar 
By $<0$

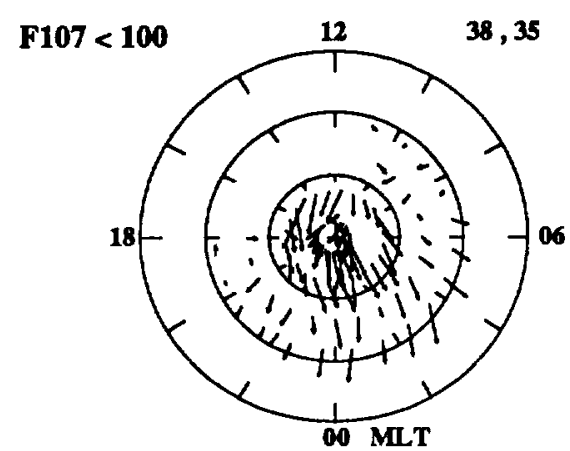

$100<\mathrm{F} 107<200$

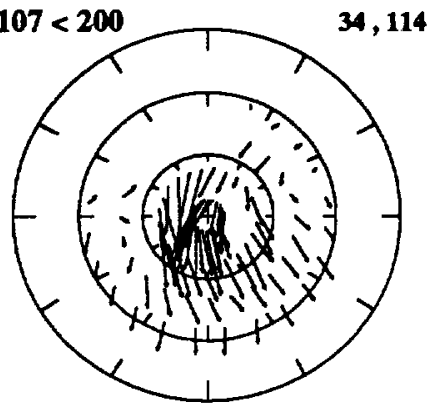

By $>0$

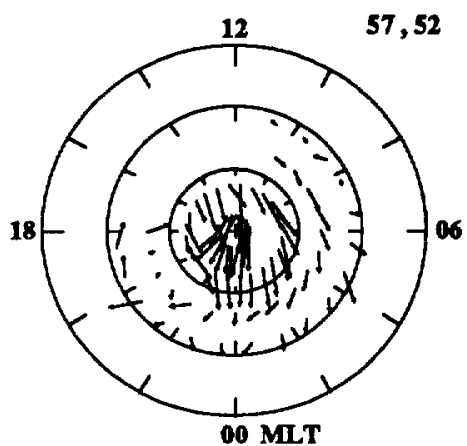

$00 \mathrm{MLT}$

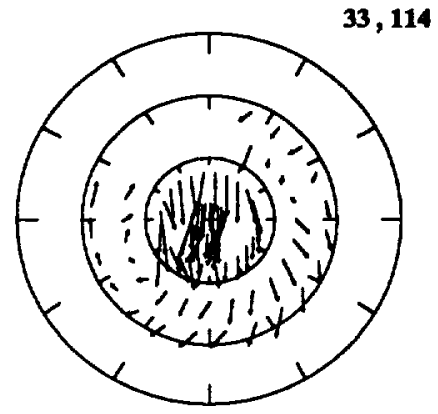

33,114

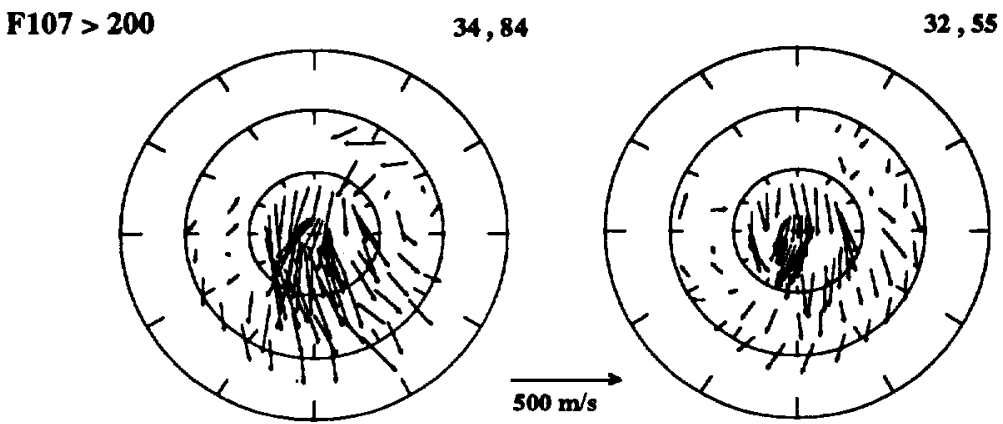

Figure 9. Dependence of the polar cap wind on the east-west $\left(B_{y}\right)$ component of the interplanetary magnetic field. The panels to the left represent data obtained for conditions of persistent negative $B_{y}$, and the panels to the right represent data obtained for conditions of persistent positive $B_{y}$ (see text for data selection criteria). The data are plotted for low $\left(F_{10.7}<100\right)$, medium $\left(100<F_{10.7}<200\right)$, and high $\left(F_{10.7}>200\right)$ levels of solar EUV flux index. The number of nights included in each average is given just above and to the right of each polar dial (first number for Thule, second number for Søndre Strømfjord).

maximum than at solar minimum, as would be expected from consideration of the importance of ionization levels for strong ion drag forcing. The greatest magnitude winds during solar maximum $\left(F_{10.7}>200\right)$ are observed in the dusk sector for $B_{y}$ negative and in the dawn sector for $B_{y}$ positive, consistent with previous satellite-based studies [McCormac et al., 1985; Thayer et al., 1987]. This change is not so evident for the moderate and low solar activity levels.

The data of Figure 9 are particularly significant in that they imply relatively strong cyclonic polar cap flows for negative $B_{y}$. Thayer et al. [1987] previously used DE 2 data to indicate that the anticyclonic neutral vorticity associated with the dusk cell of the ion convection pattern was always greater than the cyclonic vorticity associated with the dawn cell of ion convection, even for $B_{y}$ negative conditions. Our groundbased averages do not support the view that the anticyclonic flow always dominates inside the polar cap. The cyclonic mean winds for $B_{y}$ negative shown in Figure 9 imply strong influence by the dawn ion convection cell.

\subsection{Thermospheric Temperature Observations}

The thermospheric temperature observations from Thule have been averaged into daily (24-hour) bins and plotted as a function of time over the 6-year observing period. The temperatures are assigned to an altitude of $240 \mathrm{~km}$ (i.e., values of a few to several percent below exospheric values), consistent with the recommendations of the aeronomical study by McCormac et al. [1987b]. Figure 10 shows the dailyaveraged neutral temperatures together with error bars representing the standard deviations about each daily mean value. The figure also shows the $F_{10.7}$ solar index for the same period. As can be seen, the polar cap upper thermospheric temperature is a strong function of solar cycle, rising from values of near $500 \mathrm{~K}$ at solar minimum to values in 




Figure 10. Daily-averaged neutral thermospheric temperatures measured at Thule Air Base as a function of year day number between 1986 and 1991 (86035 denoles the 35th day in 1986). The errors represent standard deviations about each daily mean. The figure also shows the corresponding solar EUV flux index $F_{10.7}$ index for the period.

excess of $1600 \mathrm{~K}$ at solar maximum. The large amount of dayto-day variability evident in these data is primarily due to the effects of geomagnetic activity.

To provide an improved and more quantitative description of polar cap temperature variations, we have used all available temperature measurements and have binned the data according to $F_{10.7}$ and $K p$ indices. Figure 11 shows the results of two such binning exercises. In Figure $11 \mathrm{a}$, hourly-averaged temperature observations are plotted against $F_{10.7}$ for the specific level of geomagnetic activity denoted by $K p=3$. Thus we have attempted to remove the geomagnetic activity effect to focus on the purely solar activity dependence. The data show a positive correlation as expected, but with significant variability. A straight-line regression analysis gives a temperature $T$ defined by $T(K)=836+3.1 F_{10.7} \quad(R=0.68)$. The variability about this line is presumably due to dynamical effects (diurnal, IMF-dependent effects, etc. ) such as those discussed by McCormac et al. [1988], as well as due to the known inadequacy of the proxy indices to provide quantitative measures of activity levels.

Figure $11 \mathrm{~b}$ depicts the more purely geomagnetic activity dependence. In this plot, we have selected data within a small range of $F_{10.7}$ values and have plotted the data as a function of $K p$. The regression line here yields a value of $T$ given by $T(K)$ $=1215+7.77 K p(R=0.36)$. The temperature shows a relatively weak positive correlation with geomagnetic activity as denoted by $K p$. We note the lower value of the correlation coefficient and the large degree of variability about the regression line.

Plate 1 provides an overview of the entire database of temperatures plotted as functions of $F_{10.7}$ and ap in a twodimensional format. The linear geomagnetic index ap has been used here instead of $K p$ to facilitate comparison with the mass spectrometer/incoherent scatter (MSIS-90) empirical model. The data of Plate 1 have been binaveraged, interpolated to eliminate missing data, and smoothed. In this manner, we have reduced the degree of variability in the data in order to provide a smooth representation of the average dependence of polar cap temperature to geomagnetic and solar activity, ranging from solar minimum to solar maximum and from extremely quiet to extremely disturbed geomegnetic conditions. Over 40,000 individual observations were used to generate this image. Plate $1 b$ provides a comparison with the
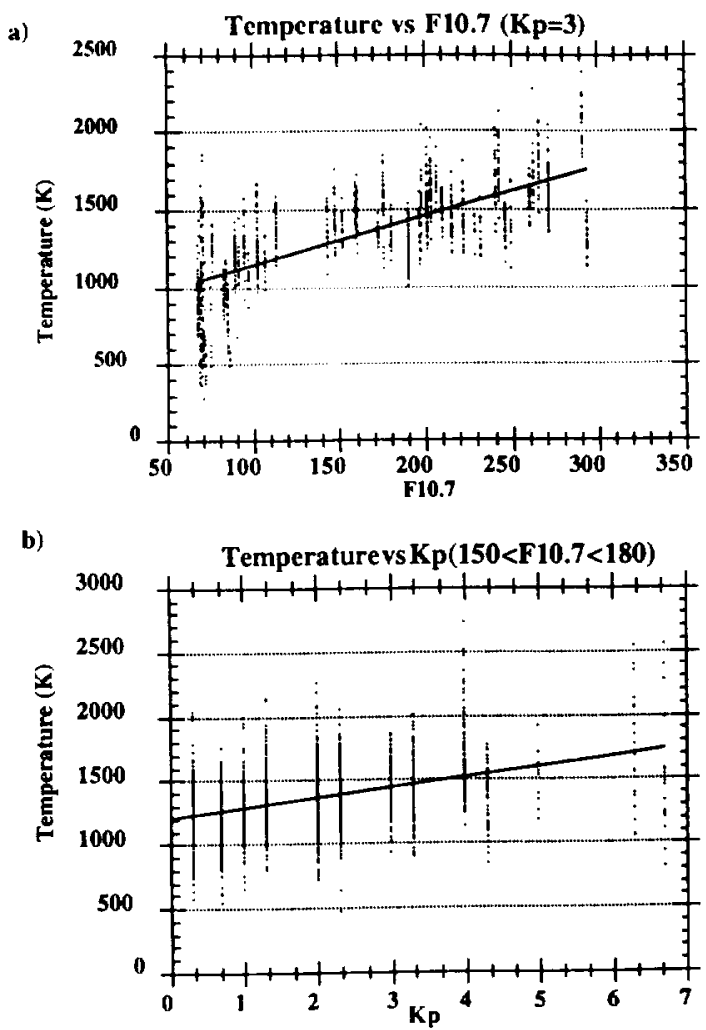

Figure 11. Thermospheric temperatures measured over Thule Air Base from 1985 to 1991. The data have been sorted and binned according to the corresponding solar EUV flux index $(F, 0,7)$. (a) The dependence of the measured temperatures on the $F_{10.7}$ index for $K p=3$. (b) The dependence of the measured temperatures on the $K p$ index for the specified interval of $F_{10.7}$. 
a) Thule Temperatures 1986-91 (K)

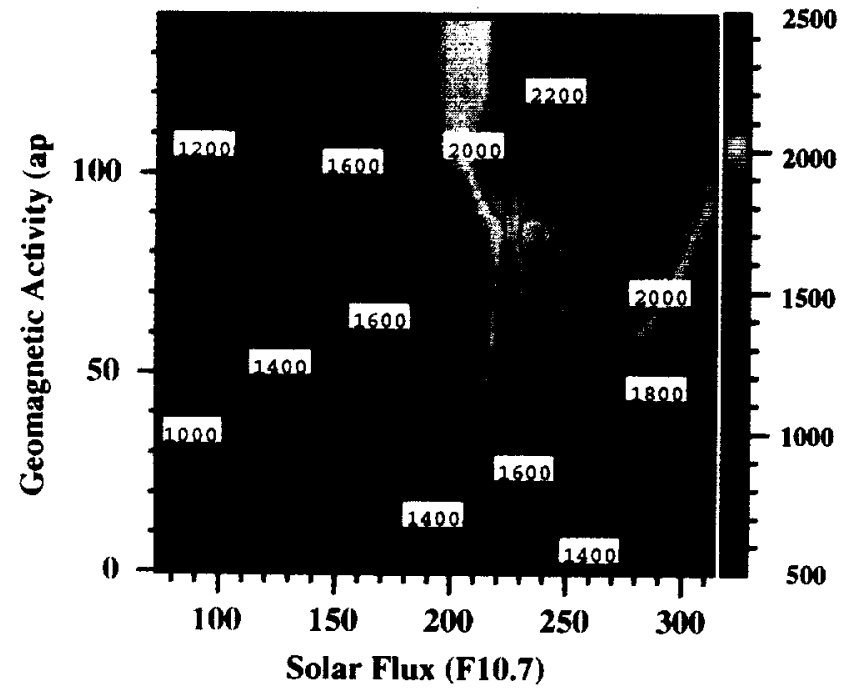

b) MSIS-90 Temperatures at $240 \mathrm{~km}(\mathrm{~K})$

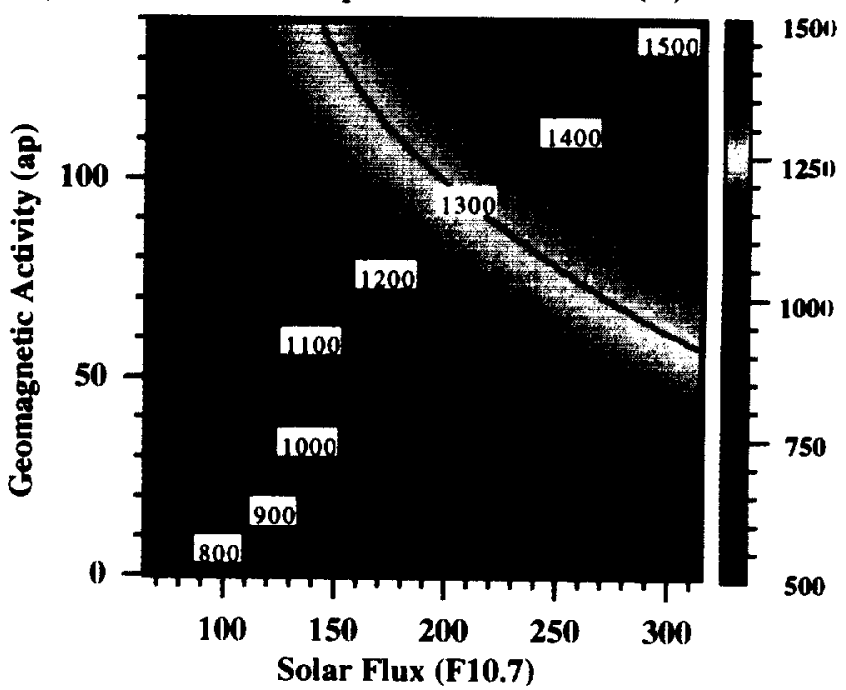

Plate 1. (a) Binned and averaged thermospheric temperatures (in kelvins) over Thule Air Base between 1985 and 1991 as a function of the solar EUV flux activity index $F_{10.7}$ and the geomagnetic index ap. The data have been interpolated to remove $g$ aps in coverage and smoothed. (b) Predictions from the MSIS-90 model for the corresponding geophysical conditions.

predictions of the MSIS-90 model, evaluated at an altitude of $240 \mathrm{~km}$ for the same geophysical conditions.

The observations of Plate 1 a illustrate the expected monotonic, positive correlation of thermospheric temperature with both geomagnetic and solar activity. Mean temperatures range from about $700 \mathrm{~K}$ at solar minimum, quiet times to over $2200 \mathrm{~K}$ for large storms at solar maximum. It is noteworthy that the highest temperatures require elevated levels of both geomagnetic and solar activity, sometimes termed a "lightbulb effect". Thus, for example, a large storm at solar minimum can only raise mean temperatures to about $1300 \mathrm{~K}$. Similarly, very high levels of solar activity, in the absence of high geomagnetic activity, lead to thermospheric temperatures of only about $1400 \mathrm{~K}$. However, when both indices are elevated, temperatures can readily exceed $2000 \mathrm{~K}$. The pendulous region in Plate $1 \mathrm{a}$ is not considered to be a reproducible geophysical feature, but the result of limited statistical accuracy of the averages in the particular solar EUV flux range near $F_{10.7}=225$ (that is, it is due to one particular date sequence). The comparison with the MSIS-90 model indicates that the model severely underestimates the thermospheric temperatures for high combined solar and geomagnetic activity. The model predictions are much closer to the observations when only one of the two indices is high. The MSIS-90 temperatures at high geomagnetic and high solar activity underestimate thermospheric temperature by up to 700 K. This discrepancy may lead to significant errors in calculations of high-latitude satellite drag and atmospheric density using MSIS for active conditions at solar maximum.

\section{Theoretical Analysis}

To investigate the physical mechanisms responsible for the observed polar cap thermospheric climatology, we have conducted a term-by-term analysis of outputs from the NCAR TIGCM [Roble et al., 1988b]. This analysis utilizes the diagnostic processor developed by Killeen and Roble [1984], which enables individual terms in the momentum and energy equations solved by the NCAR model to be examined and intercompared quantitatively. Two model runs were used, for solar maximum and solar minimum conditions and for moderate levels of geomagnetic activity $(K p=3)$. The model runs were for diumally reproducible conditions.

The calculated momentum forcing terms at upper thermospheric altitudes at the location of the Thule observatory are shown in Figure 12. The momentum equation in this case is broken into the (geographic) zonal and meridional components for analysis. Four panels show the zonal wind at solar maximum (Figure 12a); meridional wind at solar maximum (Figure 12b); zonal wind at solar minimum (Figure 12c); and meridional wind at solar minimum (Figure 12d). The momentum forcing terms (in units of $\mathrm{m} \mathrm{s}^{-2}$ ) are plotted as a function of UT.

At solar maximum (Figures $12 \mathrm{a}$ and $12 \mathrm{~b}$ ), the momentum balance is determined by the combination of the nonlinear momentum advection term, the pressure gradient term, the ion drag term, the viscous term, and the Coriolis term. All terms are of significance in the momentum balance, but the Coriolis and advection terms have the greatest magnitudes, with the pressure gradient term being also of importance, particularly for the zonal momentum balance. The individual terms can exceed $0.05 \mathrm{~m} \mathrm{~s}^{-2}$ at times, but owing to term cancelation, the overall balance leads to much smaller resultant accelerations $\left(-0.01 \mathrm{~m} \mathrm{~s}^{-2}\right)$. It is noteworthy that the ion drag term, normally thought of as the dominant term for high-latitude thermospheric dynamics, is relatively small compared with the advection and Coriolis terms. This implies that the polar cap wind is not strongly forced in situ but basically "coasts" across the polar cap driven by ion drag forcing upwind near the cusp region. Of course, if the polar cap ions were to moderate their own antisunward speeds abruptly, then ion drag could quickly come into play. The diurnally reproducibie model runs used here do not allow for such abrupt changes and therefore only elucidate the "average" situation with steady geomagnetic forcing.

At solar minimum (Figures $12 c$ and $12 \mathrm{~d}$ ), the force balance 
a)

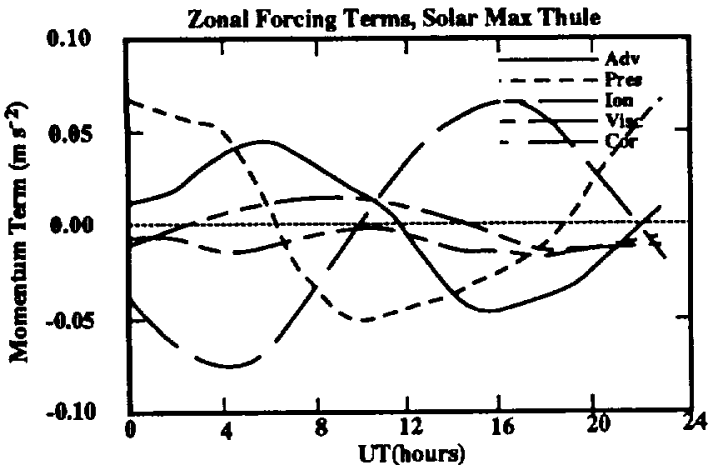

c)

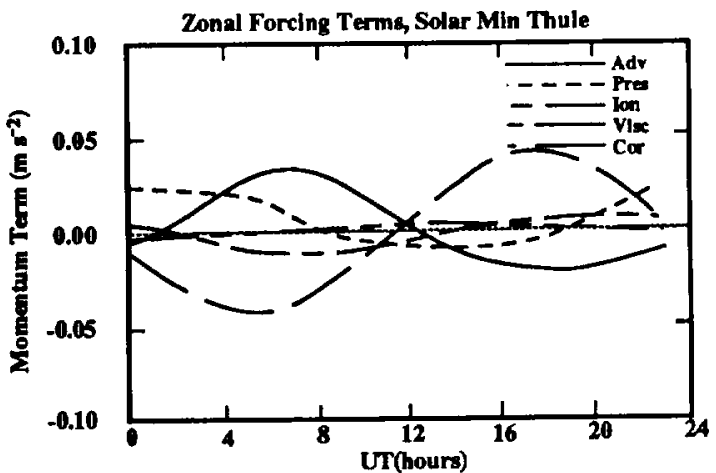

b)

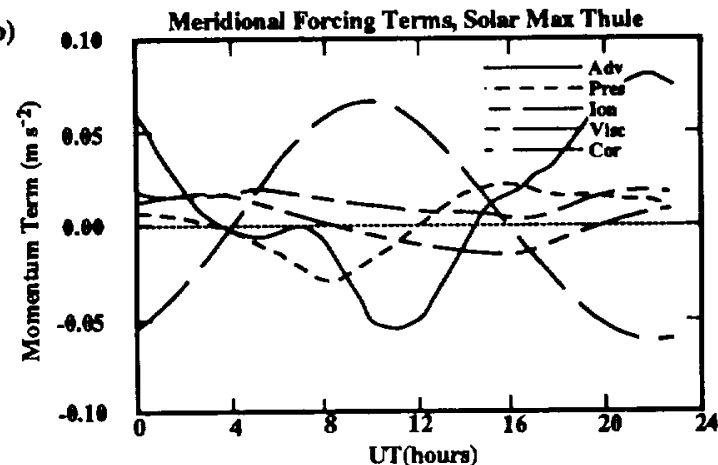

d)

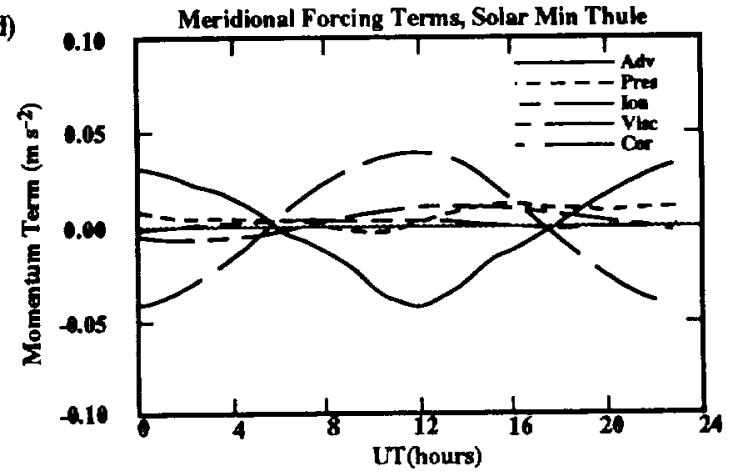

Figure 12. Comparison of momentum forcing terms (in units of $\mathrm{m} \mathrm{s}^{-2}$ ) calculated from two diumallyreproducible runs of the NCAR TIGCM for the location of the Thule Air Base (upper thermospheric altitudes). The terms are plotted as a function of UT: nonlinear momentum advection (Adv); pressure gradient (pres); ion drag (ion); viscous drag (visc); and Coriolis term (Cor). The four panels depict (a) zonal momentum balance for solar maximum; (b) meridional momentum balance for solar maximum; (c) zonal momentum balance for solar minimum; and (d) meridional momentum balance for solar minimum. The zonal and meridional directions are in geographic coordinates.

has a similar form, but with markedly reduced magnitudes (approximately a factor of 2) compared with the solar maximum situation. Again, nonlinear momentum advection, the Coriolis term, and the pressure gradient force are the most important, with ion drag of lesser importance for the momentum budget. Once again, for solar minimum conditions the analysis indicates that the neutral winds appear to coast across the polar cap for conditions of steady geomagnetic forcings. Future work will consider the case of nonsteady state forcings.

Figure 13 shows the calculated thermal balance over Thule for solar maximum (Figure 13a) and solar minimum (Figure 13b) conditions. The heat balance is controlled by the combination of four significant terms: adiabatic expansion and compression (labeled stab); downward conduction (labeled down); nonlinear heat advection (labeled adv); and Joule heating (labeled Joul). For these polar night conditions, there is no direct solar EUV heating. For both solar maximum and solar minimum, the advection term is the greatest, with the adiabatic expansion and compression term the second greatest. Downward thermal conduction is a significant energy sink at these altitudes. The thermal balance indicates that the diumal temperature dependence reported by McCormac et al. [1988] is indeed driven by the advection term, which has a strong diurnal signature (counterbalanced by the adiabatic term, which offsets the advective forcing of polar cap temperature).
Because of the obvious importance of the advection term in both momentum and energy balances in the polar cap thermosphere, we have calculated several back trajectories from the same runs of the NCAR TIGCM to determine the spatial origin of the thermospheric air that passes over Thule. Figure 14 shows the results of these calculations for solar minimum (Figure 14a) and solar maximum (Figure 14b). In both cases, four trajectories are shown, corresponding to air that arrives over Thule at $0000,0600,1200$, and 1800 UT, respectively. The trajectories are labeled with UT hour markers to indicate the distance traveled as the air parcels approach Thule. Since the plot is in geomagnetic polar coordinates, all trajectories end near the middle of the polar dial. For the calculated solar minimum trajectories, 6 hours prior to arrival over Thule, the air parcels were all in the region of the dayside polar cap, in some cases probably within the polar cusp region. In the case of the solar maximum trajectories, the parcels came from the dawn sector. As can be inferred from the spacing of the hour markers on the trajectories, much of the acceleration of the air passing over Thule occurs well upstream in regions close to the cusp and dawn sector auroral zone. This is consistent with the relatively small magnitude of the ion drag forcing term in Figure 12 and supports the idea that the polar cap air is basically coasting across the region (i.e., with no large net in situ acceleration). The quite different spatial origins of the air parcels passing over Thule (Figure 14) indicate that much of the variability in polar cap weather 
a)

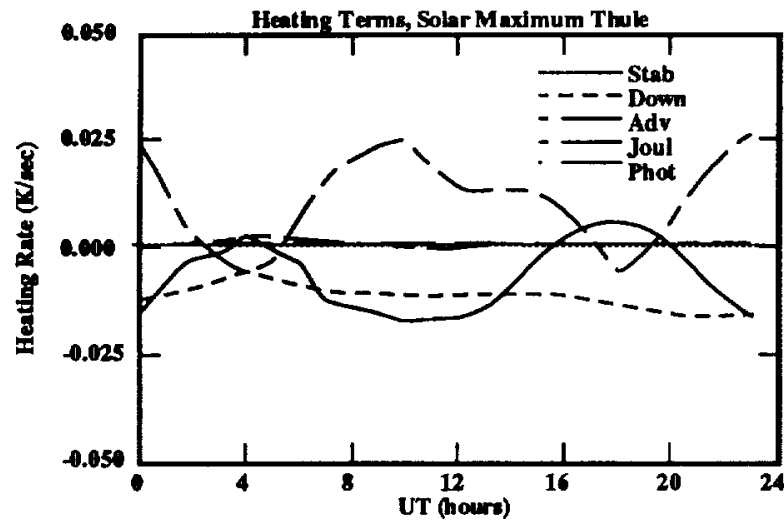

b)

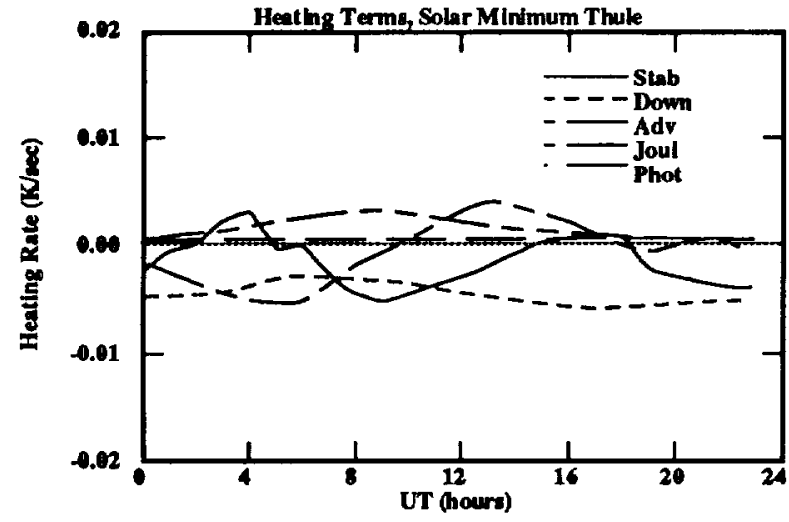

Figure 13. Comparison of heating terms (in units of kelvins/second) calculated from two diurnally reproducible runs of the NCAR TIGCM for the location of the Thule Air Base (upper thermospheric altitudes). The terms are plotted as a function of UT: heating and cooling due to adiabatic expansion and compression (Stab); downward thermal conduction (Down); horizontal heat advection (Adv); Joule heating (Joul); and solar EUV heating (Phot). The two panels depict (a) thermal balance for solar maximum and (b) thermal balance for solar minimum. Note the change in vertical scale between the two panels.

reported in this paper can be ascribed to (1) variations in trajectory geometries of air parcels and (2) variations in heating and momentum forcing terms in auroral regions (dayside and dawn sector) directly subject to auroral forcings.

\section{Summary}

Data from two ground-based Fabry-Perot interferometers located at Thule and Søndre Strømfjord, Greenland have been analyzed to study upper thermospheric climatology in the central region of the geomagnetic polar cap. Various factors make this data set unique and of particular value. These factors are (1) the proximity of the Thule observing station to the geomagnetic pole, enabling polar cap thermospheric dynamics to be monitored over a long interval; (2) the continuous nature of the coverage due to the high geographic latitude and polar night conditions; and (3) the long-term nature of the combined database, enabling solar cycle, geomagnetic activity, and IMF effects to be separately investigated. The analysis of the long time series of observations of winds and temperatures, coupled with an associated theoretical study of momentum and heating terms, has led to the following principal conclusions.

1. The upper thermospheric winds in the geomagnetic polar cap have a fundamental diumal character, with typical wind speeds of $200 \mathrm{~m} \mathrm{~s}^{-1}$ at solar minimum, rising to up to about $800 \mathrm{~m} \mathrm{~s}^{-1}$ during high geomagnetic activity at solar maximum.

2. The polar cap winds generally blow in the antisunward direction, but are interrupted by episodes of modified wind speed and altered direction associated with changes in the orientation of the interplanetary magnetic field (IMF).

3. The central polar cap, antisunward wind speed is found to be a strong function of both solar and geomagnetic activity. The maximum average polar cap antisunward wind is found to respond roughly linearly with $K p$ according to the expression $u_{\max }=109+81 K p \mathrm{~m} \mathrm{~s}^{-1}(R=0.975)$ for average solar activity $\left(100<F_{10.7}<200\right)$ and roughly linearly with $F_{10.7}$ according to the expression $u_{\max }=155+1.13 F_{10.7} \mathrm{~m} \mathrm{~s}^{-1}(R$ $=0.943)$ for average geomagnetic activity $(2<K p<5)$. The wind shows an anticorrelation with $F_{10.7}$ at the lowest $K_{p}$ values, but is positively correlated with both $K p$ and $F_{10.7}$ for all other cases.

4. The curvature in the mean polar cap winds shows a pronounced dependence on the sign of the east-west $\left(B_{y}\right)$ component of the IMF, with signatures of both cyclonic and anticyclonic vorticity being present associated with the dawn and dusk ion convection cells, respectively.

a)

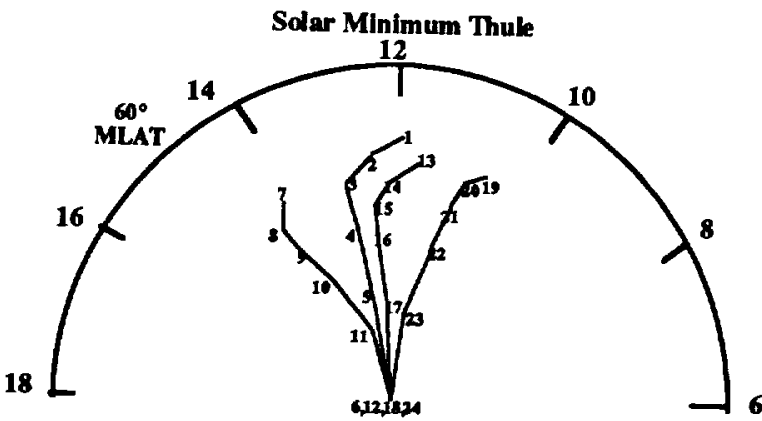

b)

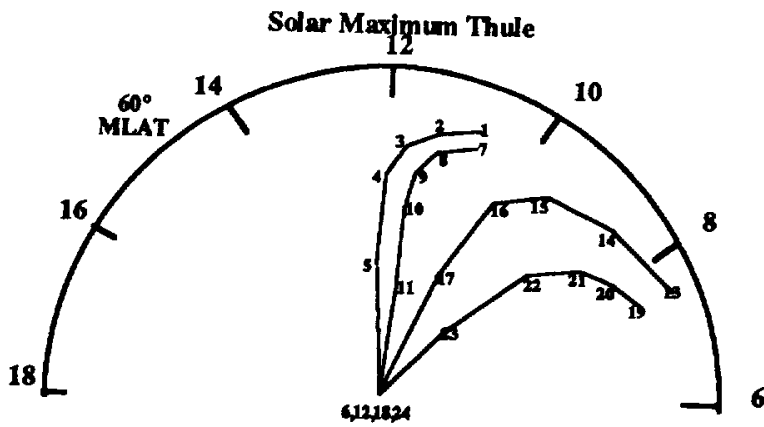

Figure 14. Calculated backward air parcel trajectories from two diurnally reproducible runs of the NCAR TIGCM for parcels that arrive at the model grid point closest to the location of the Thule Air Base (upper thermospheric altitudes). Four 6-hour trajectories are calculated in each case, corresponding to the air parcels that arrive at Thule at 0000 , 0600,1200 and 1800 UT. The back trajectories are labeled with hourly UT markers. The polar dial is in geomagnetic polar coordinates with the outer circle at $60^{\circ} \mathrm{N}$ magnetic latitude. The two panels show trajectories calculated for (a) solar minimum conditions and (b) solar maximum conditions. 
5. The polar cap temperatures show variations with both solar and geomagnetic activity, with temperatures near $800 \mathrm{~K}$ for low $K p$ and $F_{10.7}$ and greater than $2000 \mathrm{~K}$ for high $K p$ and $F_{10.7}$. The observed temperatures are significantly greater than those predicted by the MSIS-90 model for high activity conditions.

6. Theoretical analysis based on the NCAR TIGCM indicates that the mean antisunward upper thermospheric winds, driven by upstream ion drag, basically "coast" across the polar cap. The relatively small changes in wind velocity and direction within the polar cap are induced by a combination of forcing terms of commensurate magnitude, including the nonlinear advection term, the Coriolis term, and the pressure gradient term. The polar cap thermospheric thermal balance is dominated by horizontal advection and adiabatic and thermal conduction terms.

Ackmowledgments. This work was supported by NSF grants ATM9308157, ATM-9400877, and ATM-9402289 and by NASA grant NAGW-3457 to the University of Michigan. The Thule observatory was established and supported for many years by the Air Force under Phillips Leboratory contracts F19628-83-K-0035 and F19628-89-K0026 to the University of Michigan. The authors wish to thank the many individuals who have contributed in important ways to the establishment of the Thule and Sondre Stromfjord optical facilities and to their longterm operation. These individuals include J. W. Meriwether Jr., F. G. McCormac, R. M. Johnson, J. P. Thayer, R. W. Cannata, E. Trudell, B. Nardi, S. Carr, and E. J. Weber. The authors are also grateful to R. G. Roble for providing access to the NCAR TIGCM and for numerous discussions.

The Editor thanks B. A. Tinsley and H. Rishbeth for their assistance in evaluating this paper.

\section{References}

Aruliah, D. L., D. Rees, and A. Stcen, Seasonal and solar-cycle variations in high-latitude themospheric winds, Geophys. Res. Lett. $18,1983-1986,1991$.

Buonsanto, M. J., Neutral winds in the thermosphere at midlatitudes over a full solar cycle: A tidal decomposition, J. Geophys. Res., 96, 3711$3724,1991$.

Bumside, R. G., and C. A. Tepley, Optical observations of thermospheric neutral winds at Arecibo between 1980 and 1987, J. Geophys. Res., 94, 2711-2716, 1989.

Deng, W, T. L. Killeen, A. G. Burns, and R. G. Roble, The flywheel effect: Ionospheric currents after a geomagnetic storm, Geophys. Res. Lett., 18, 1845-1848, 1991.

Deng, W., T. L. Killeen, A. G. Bums, R. G. Roble, J. Slavin, L. E Wharton, and R. A. Heelis, The effects of neutral inertia on ionospheric currents in the high latitude thermosphere following a geomagnetic storm, J. Geophys. Res., 98, 7775-7790, 1993.

Fesen, C. G., R. G. Roble, and E. C. Ridley, Thermospheric tides at equinox: Simulations with coupled composition and suroral forcings, 1, Diumal component, J. Geophys. Res., 96, 3647-3662, 1991.

Fuller-Rowell, T. J., D. Rees, S. Quegan, R. J. Moffett, and G. J. Bailey, Simulations of the seasonal and universal time variations of the highlatitude thermosphere and ionosphere using a coupled, threedimensional model, Pure Appl, Geophys., 127, 189-217, 1988.

Fuller-Rowell, T. J., D. Rees, B. A. Tinsley, H. Rishbeth, A. S. Rodger, and $S$. Quegan, Modelling the response of the thermosphere and ionosphere to geomagnetic stoms: Effects of a mid-latitude heat source, Adv. Space Res., 10, 215-224, 1990.

Gary, J. B., R. A. Heelis, W. B. Hanson, and J. A. Slavin, Field-aligned Poynting flux observations in the high-latitude ionosphere, $J$. Geophys. Res., 99, 11417-11427, 1994.

Hagan, M. E., Quiet time upper thermospheric winds over Millstone Hill between 1984 and 1990,J. Geophys. Res., 98, 3731-3739, 1993.

Hays, P. B., T. L. Killeen, N. W. Spencer, L. E. Wharton, R. G. Roble, B. E. Emery, T. J. Fuller-Rowell, D. Rees, L. A. Frank, and J. D. Craven, Observations of the dynamics of the polar thermosphere, $J$. Geophys. Res., 89, 5597-5612, 1984.

Hedin, A. E., et al., Revised global model of thermosphere winds using satellite and gnound-based observations, J. Geophys. Res. , 96, 7657 7688, 1991.

Hedin, A. E., M. J. Buonsanto, M. Codrescu, M.-L. Duboin, C. G. Fesen, M. E. Hagan, K. L. Miller, and D. P. Sipler, Solar activity variations in midlatitude thermospheric meridional winds, J. Geophys. Res., 99, 17601-17608, 1994.

Heppner, J. P., and N. C. Maynard, Empirical high latitude electric field models, J. Geophys. Res., 92, 4467-4489, 1987.

Hermandez, G., and T. L. Killeen, Optical measurements of winds and temperatures in the upper atmosphere. in COSPAR International Reference Atmosphere: 1986, I. Thermosphere models, Adv. Space Res., 8, 149-214, 1988.

Hemandez, G., and R. G. Roble, The geomagnetic quiet time nighttime thermospheric wind pattern over Fritz Peak Observatory during solar cycle minimum and maximum, J. Geophys. Res., 89, 327-337, 1984.

Hernandez, G., R. W. Smith, R. G. Roble, J. Cress, and K. C. Clark, Thermospheric dynamics at the south pole, Geophys. Res. Lett., 17. $1255-1258,1990$.

Hemandez, G., F. G. McCormac, and R. W. Smith, Austral thermospheric wind circulation and interplanetary magnetic field orientation, J. Geophys, Res., 96, 5777-5783, 1991.

Johnson, R. M., Lower-thermospheric neutral winds at high latitude determined from incoherent scatter measurements: A review of techniques and observations, Adv. Space Res., 10, 261-275, 1990.

Johnson, R. M., and J. G. Luhmann, High-latitude mesopause neutral winds and geomagnetic activity: A cross-correlation analysis, $J$. Geophys. Res., 90, 8501-8506, 1985.

Johnson, R. M., and T. S. Virdi, High-latitude lower thermospheric neutral winds at EISCAT and Sondre Stromfjord during LTCS $1, J$. Geophys. Res., 96, 1099-1116, 1991.

Killeen, T. L., and P. B. Hays, Doppler line profile analysis for a multichannel Fabry-Perot interferometer, Appl. Opt., 23, 612, 1984.

Killeen, T. L., and R. G. Roble, An analysis of the high-latitude thermospheric wind pattern calculated by a thermospheric general circulation model, 1, Momentum forcing, J. Geophys. Res., 89, 7509$7522,1984$.

Killeen, T. L, and R. G. Roble, Thermosphere dynamics: Contributions from the first 5 years of the Dynamics Explorer Program, Rev. Geophys., 26, 329-367, 1988.

Killeen, T. L., B. C. Kennedy, P. B. Hays, and D. H. Ceckowski, An image plane detector for the Dynamics Explorer Fabry-Perot interferometer, Appl. Opt., 22, 3503, 1983.

Killeen, T. L. R. A. Heelis, P. B. Hays, N. W. Spencer, and W. B. Hanson, Neutral motions in the polar thermosphere for north ward interplanetary magnetic field, Geophys. Res. Lett., 12, 159-162, 1985.

Killeen, T. L., et a., Mean neutral circulation in the winter polar $F$ region, J. Geophys. Res., 91, 1633-1649, 1986.

Killeen, T. L., R. G. Roble, and N. W. Spencer, A computer model of global thermospheric winds and temperatures, Adv. Space Res., 7, 207-215, 1987.

Killeen, T. L., F. G. McCormac, A. G. Burns, J. P. Thayer, R. M. Johnson and R. J. Niciejewski, On the dynamics and composition of the high-latitude thermosphere, J. Aimos. Terr. Phys., 53, 797-815, 1991.

Killeen, T. L., B. Nardi, P. N. Purcell, R. G. Roble, T. J. Fuller-Rowell, and D. Rees, Neutral winds in the lower thermosphere from Dynamics Explorer 2, Geophys. Res. Lett., 11, 1093-1096, 1992.

Lyons, L. R., T. L. Killeen, and R. L. Walterscheid, The neutral wind "flywheel" as a source of quiet time, polar cap currents, Geophys. Res. Lett., 12, 101-104, 1985.

McCormac, F. G., and R. W. Smith, The influence of the interplanetary magnetic field $Y$-component on ion and neutral motions in the polar thermosphere, Geophys. Res. Lell., 11, 935-938, 1984.

MoCormac, F. G. T. L. Killeen, E. Gombosi, P. B. Hays, and N. W. Spencer, Configuration of the high-latitude thermosphere neutral circulation for IMF B yegative and positive, Geophys. Res. Lett., 12, 155-158, 1985

McCormac, F. G., T. L. Killeen, J. P. Thayer, G. Hernandez, C. R. Tschan, J. J. Ponthieu, and N. W. Spencer, Circulation of the polar thermosphere during geomagnetically quiet and active times as observed by Dynamics Explorer 2, J. Geophys. Res., 92, 10133 10139, 1987a.

McCormac, F. G., T. L. Killeen, B. Nandi, and R. W. Smith, How close are ground-based Fabry-Perot thermospheric wind and temperature measurements to exospheric values? A simulation study. Planet. Space Sci., 35, 1255-1265, $1987 \mathrm{~b}$.

McCormac, F. G., T. L Killeen, A. G. Bums, J. W. Meriwether Jr., R. 
G. Roble, L. E. Wharton, and N. W. Spencer, Polar cap diurnal temperature variations: Observations and modeling, J. Geophys. Res., 93, 7466-7477, 1988.

McCormac, F. G., T. L. Killeen and J. P. Thayer, The influence of IMF $B_{y}$ on the high-latitude thermospheric circulation during northward MMF, J. Geophys. Res., 96, 115-128, 1991.

Meriwether, J. M., Jr., C. A. Tepley, S. A. Price, and P. B. Hays, Remote ground-based observations of terrestrial airglow emissions and thermospheric dynamics at Calgary, Alberta, Canada, Opt. Eng., 22, $128,1983$.

Meriwether, J. W., Jr., P. Shih, T. L. Killeen, V. B. Wickwar, and R. G. Roble, Nighttime thermospheric winds over Sondre Stromfjord, Greenland, Geophys. Res. Lelt., 11, 931-934, 1984.

Meriwether, J. W., Jr., T. L Killeen, F. G. McCormac, A. G. Bums and R. G. Roble, Thermospheric winds in the geomagnetic polar cap for solar minimum conditions, J. Geophys. Res., 93, 7478-7492, 1988.

Niciejewski, R. J., T. L. Killeen, R. M. Johnson, and J. P. Thayer, The behavior of the high-latitude $F$-region neutral thermosphere in relation to IMF parameters, Adv. Space Res., 12, 215-218, 1992.

Niciejewski, R. J., T. L. Killeen, and Y. Won, Observations of neutral winds in the polar cap during northward IMF, J. Almos. Terr. Phys., 56, 285-295, 1994.

Ponthieu, J.-J., T. L. Killeen, K. M. Lee, G. R. Carignan, W. R. Hoegy, and L. H. Brace, Ionosphere-thermosphere momentum coupling at solar maximum and solar minimum from DE-2 and AE-C data, Phys. Scr., 37, 447-454, 1988.

Rees, D., and T. J. Fuller-Rowell, Comparison of theoretical models and obaervations of the thermosphere and ionosphere during extremely disturbed geomagnetic conditions during the last solar cycle, Adv. Space Res., 7, 27-38, 1987.

Rees, D., T. J. Fuller-Rowell, and R. W. Smith, Measurements of highlatitude thermospheric winds by rocket and ground-based techniques and their interpretation using a three-dimensional time-dependent dynamical model, Planet. Space Sci., 28, 919-932, 1980.

Rees, D., R. W. Smith, P. J. Charleton, F. G. McCormac, N. Lloyd, and A. Steen, The generation of vertical thermospheric winds and gravity waves at auroral latitudes, 1, Observations of vertical winds, Planet. Space Sci., 32, 667-684, 1984a.

Rees, D., M. F. Smith, and R. Gordon, The generation of vertical thermospheric winds and gravity waves at auroral latitudes, 2 , Theory and numerical modeling of vertical winds, Planet. Space Sci., 32, 685-705, 1984b.

Rees, D., T. J. Fuller-Rowell, R. Gordon, J. P. Heppner, N. C. Maynard, N. W. Spencer, L. E. Wharton, P. B. Hays, and T. L. Killeen, A theoretical and empirical study of the response of the high-latitude thermosphere to the sense of the " $Y$ " component of the interplanetary magnetic field, Planet. Space Sci., 34, 1-40, 1986.

Rees., D., N. D. Lloyd, T. J. Fuller-Rowell, and A. Steen, Observations of the variations of thermospheric winds in northem Scandinavia between 1980 and 1986. A study of geomagnetic effects in the last solar cycle, Adv. Space Res., 7, 39-48, 1987.

Rees, D., S. Quegan, R. J. Moffeu, G. J. Bailey, and T. J. Fuller-Rowell, Simulations of the behaviour of the polar thermosphere and ionosphere for northwand IMF, J. Almos. Terr. Phys., 56, 297-318, 1994.

Roble, R. G., B. A. Emery, R. E. Dickinson, E. C. Ridley, T. L. Killeen, P. B. Hays, G. R. Carignan, and N. W. Spencer, Thermospheric circulation, temperature, and compositional structure of the southem hemisphere polar cap during October-November 1981, J. Geophys. Res., 89, 9057-9068, 1984.

Roble, R. G., T. L Killeen, N. W. Spencer, R. A. Heelis, P. H. Reiff, and J. D. Winningham, Thermospheric dynamics during November 21-22, 1981: Dynamics Explorer measurements and themospheric general circulation model predictions, J. Geophys. Res., 93, 209-245, $1988 \mathrm{a}$.

Roble, R. G., E. C. Ridley, A. D. Richmond, and R. E. Dickinson, A coupled thermosphere/ionosphere general circulation model. Geophys. Res. Lett., 15, 1325-1328, 1988 b.

Sica, R. J., M. H. Rees, G. J. Romick, G. Hemandez, and R. G. Roble, Auroral zone thermospheric dynamics, 1, Averages, J. Geophys. Res., 91, 3231-3244, 1986.

Sica, R. J., G. Hemandez, G. J. Romick, M. H. Rees, and R. G. Roble, Auroroal zone thermospheric dynamics, 2 , Individual nights, $J$. Geophys. Res., 91, 13593-13611, $1986 \mathrm{~b}$.

Sica, R. J., G. Hemandez, B. A. Emery, R. G. Roble, R. W. Smith, and $M$. H. Rees. The control of auroral zone dynamics and thermodynamics by the interplanetary magnetic field dawn-dusk ( () component, J. Geophys. Res., 94, 11921-11932, 1989.

Smith, R. W., K. Henriksen, C. S. Deehr, D. Rees, F. G. McCormac, and G. G. Sivjec, Thermospheric winds in the cusp: Dependence of the latitude of the cusp, Planet. Space Sci., 33, 305-313, 1985.

Smith, R. W., D. Rees, and R. D. Stewart, Southem hemisphere thermospheric dynamics: A review, Rev. Geophys., 26, 591-622, 1988.

Smith, R. W., J. W. Meriwether Jr., G. Hemandez, D. Rees, V. Wickwar, O. De La Beaujandiere, and T. L. Killeen, Mapping the wind in the polar thermosphere: A case study within the CEDAR program, Eos Trans. AGU, 70, 168, 1989.

Stewar, R. D., R. W. Smith, D. Rees, J. R. Dudeney, and A. S. Rodger, Fint measurements of thermospheric winds in Antartica by an optical ground-based method, Nature, 317, 45-48, 1985.

Stewart, R. D., A. S. Rodger, and J. R. Dudeney, Thermospheric response to the magnetic signature of the Harang discontinuity, Planet. Space Sci., 36, 225-229, 1988.

Thayer, J. P., and T. L. Killeen, Vorticity and divergence in the highlatitude upper thermosphere, Geophys. Res. Lett., 18, 701-704, 1991.

Thayer, J. P., and J. F. Vickrey, On the contribution of themospheric neutral winds to high-latitude energetics, Geophys. Res. Lett., 19. 265-268, 1992.

Thayer, J. P., T. L. Killeen, F. G. MeCormac, C. R. Tschan, J.-J. Ponthieu, and N. W. Spencer, IMF B y-dependent neutral wind signatures for northem and southern hemispheres from Dynamics Exploner 2 data, Ann. Geophys., ser. S, A., 363-368, 1987.

$W$ ardhill, $P$., and F. Jacka, Vertical motions in the themosphere over Mawson, Antanctica, J. Almos. Terr. Phys., 48, 289-292, 1986.

Wickwar, V. B., J. W. Meriwether Jr., P. B. Hays, and A. F. Nagy, The meridional thermospheric neutral wind measured by radar and optical techniques in the auroral region, J. Geophys. Res., 89, 10987 10998, 1984.

Wiens, R. H., G. G. Shepherd, W. A. Gault, and P. R. Kosteniuk, Optical measurements of winds in the lower thermosphere, J. Geophys. Res., 93, 5973-5980, 1988.

Won, Y.-I. Studies of thermospheric neutral winds utilizing groundbased optical and radar measurements, Ph.D. thesis, Univ. of Michigan, Amn Arbor, 1994.

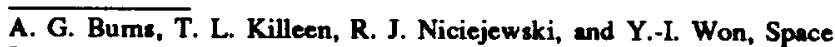
Physics Research Laboratory. University of Michigan, 2455 Hayward Street, Ann Arbor, MI 48109. (egbums@sprlc.spri.umich.edu, tkilleen@umich.edu, rickn@sprlc.sprl.umich.edu)

(Received February 14, 1995; revised April 7, 1995; accepted April 7, 1995.) 